\title{
Electoral fraud and voter turnout: An experimental study*
}

\author{
Vardan Baghdasaryan† Giovanna Iannantuoni; Valeria Maggian ${ }^{\S}$
}

\begin{abstract}
In this paper we experimentally investigate the consequences of electoral fraud on voter turnout. The experiment is based on a strategic binary voting model where voters decide whether to cast a costly vote in favour of their preferred candidate or to abstain. The electoral process is illicitly influenced by applying ballot-box stuffing. In the experiment we implement two different framings: we compare voter turnout in a neutral environment and with framed instructions to explicitly replicate elections. This approach enables us to both test the model's predictions and to estimate the framing effects of voting and fraud. Comparison of experimental results with theoretical predictions reveals over-voting, which is exacerbated when fraud occurs. Turnout increases as predicted with a moderate level of fraud while, with higher levels of electoral fraud, voters fail to recognize that the existence of a relatively larger number of "agents" voting with certainty considerably decreases the benefits of voting. Importantly, framing matters, as revealed by the higher turnout of those in the majority group, against which the fraud is applied.
\end{abstract}

JEL classification: D72, C52, C91, C92

Keywords: Laboratory experiment, Framing, Voting, Electoral fraud, Ballot box stuffing and Voter turnout.

\footnotetext{
*Acknowledgements: The authors gratefully acknowledge financial support from PRIN (20122015) "New approaches to political economics : positive political theories, empirical evidence and experiments in laboratory". Valeria Maggian's contribution to this research was also performed within the framework of the LABEX CORTEX (ANR-11-LABX-0042) of Universitè de Lyon, within the program Investissements d'Avenir (ANR-11-IDEX-007) operated by the French National Research Agency (ANR). We thank Natalia Montinari, Marie Claire Villeval, the participants at the 2016 Behavioral Models of Politics conference at the University of Pittsburgh and at the 2015 ESA European Meeting at the University of Heidelberg for useful comments. We are grateful that David K. Levine and Thomas Palfrey provided us with their data from the laboratory experiment "The paradox of voter participation? A laboratory study" (2007).

${ }^{\dagger}$ American University of Armenia and Affiliate Fellow at CERGE-EI, Prague. E-mail: vbaghdasaryan@aua.am.

${ }^{\ddagger}$ University of Milano-Bicocca. E-mail: giovanna.iannantuoni@unimib.it.

${ }^{\S}$ Corresponding author. Cà Foscari University, Department of Economics, Cannaregio 873, Fondamenta San Giobbe, 30121 Venice, Italy. E-mail: valeria.maggian@unive.it.
} 


\section{Introduction}

Since the 1990s, with the last large wave of democratization of post-Soviet and eastern European countries, the number of elections in the world has witnessed a sharp increase. At the same time, the quality of elections has deteriorated over time: while the share of elections reported to be illicitly influenced was around $15 \%$ of around 180 national level elections during the period 1980-1990, it increased to almost $40 \%$ of around 480 elections in the period $2001-2010 .^{1}$

In this paper we investigate, both theoretically and experimentally, the effects of electoral fraud on voter turnout. Our objective is twofold. First, high turnout rate is often quoted as an indirect indicator of properly organized and conducted elections. We thus provide first evidence on whether a lower participation rate is effectively associated with a higher degree of fraudulent intervention in the elections. Second, our experimental design enables us to test whether the behavioural reaction to an electoral procedure that is considered unfair also affects voter participation. Citizens may shy away from voting when the election is characterized by a fraudulent mechanism or, alternatively, they may be rather more likely to mobilize and go to the polls in order to counteract it. Evidence of electoral fraud has been provided worldwide, both in developed and in developing countries. Weak electoral identity-checking schemes were responsible for at least 42 convictions for electoral fraud in the UK in the period 2000-2007 (Wilks-Heeg, 2008) and for promoting electoral fraud in Japanese municipal elections, as shown by the natural experiment by Fukumoto and Horiuchi (2011). News reports, highlighting the risk of voter fraud in several EU countries, ${ }^{2}$ have become a fairly routine part of electoral campaigns. Douglas (2013) examines the multiplicity of election contest provisions and the procedural mechanism used to manage them in US states: the notorious hanging

\footnotetext{
${ }^{1}$ Authors' calculations based on data from Institute for Democracy and Electoral Assistance (IDEA), database on political institutions (DPI) and the Cingranelli-Richards human rights dataset (CIRI).

${ }^{2}$ EUobserver (2014): Threat of voter fraud haunts EU vote in Romania, Bulgaria and Croatia. See http://euobserver.com/eu-elections/123485
} 
chads in 2000 in Florida is an example of the US not being immune to (potential) electoral malpractices. While in developing countries electoral fraud is usually more evident and takes a wider variety of forms, from vote buying to intimidation and explicit violence, in the post-Soviet area the most common electoral malpractices are multiple voting and ballot stuffing, according to the Organization for Security and Cooperation in Europe (Bader, 2012).

In order to theoretically investigate the effects of fraud on voter turnout, we modify the conventional binary election model with costly voting to allow for fraud, where illicit intervention is promoted by only one out of two parties. Assuming that the implementation of fraud is costly (hence limited) we show that, in equilibrium, fraud might increase the turnout rate. In particular, a low level of fraud exerted in favour of the competitor with the ex-ante less support should increase turnout in both groups, whereas a higher fraudulent intervention should suppress voting motives and decrease the turnout rates to a level lower than in equilibrium without fraud.

We test our predictions in a laboratory experiment, where we compare voting behaviour in a baseline condition with respect to a situation where, respectively, a low and a high level of fraud is introduced in the elections. The baseline condition is designed in a way that allows direct comparisons with the paper by Levine and Palfrey (2007). In their laboratory experiment, they test for the effect of changing the (relative and absolute) size of the electorate of two competing groups of supporters on voter turnout: while a more numerous electorate lowers turnout rate, having closer elections increases it. Finally, they show that voters supporting the less popular alternative have higher turnout rates. We thus provide an additional validity test for their results. However, in order to analyse the effect of fraud on voting behaviour, we also introduce fraud in the elections. We investigate voters' reaction to an unfair electoral process in a framework involving a decreasing (increasing) quality of elections, where voters experience an electoral system which progressively evolves from a situation of electoral integrity (fraud) to electoral 
fraud (integrity).

We first investigate how individuals react to uneven ex-ante conditions when choosing between two featureless options standing for voting and abstention. In the Neutral treatment, the wording in the instructions is designed to induce a neutral environment; there is no mention of voting, electoral fraud or voting costs. More specifically, in the experiment, electoral fraud is introduced by adding a number of "fake" votes in favour of the minority group. ${ }^{3}$

We then examine the importance of social and psychological factors in affecting voting behaviour. ${ }^{4}$ In the Framing treatment the only modification is made with respect to the terminology used in the instructions: we explicitly refer to elections and we render the unfairness of the uneven condition more salient, by explicitly referring to "vote rigging". The experiment provides a number of noteworthy results. First, the comparison of experimental results with theoretical predictions reveals over-voting (analogous results were obtained by Levine and Palfrey (2007)). Second, as expected, limited fraudulent intervention increases the turnout and this result is observed both in the Neutral and Framing treatment. Third, extensive fraud has a significant negative impact on turnout rates, as suggested by the theoretical model, merely in the Neutral treatment, but still turnout is higher than when electoral integrity is fully assured. Fourth, in the Framing treatment, the majority group, against which the fraud is undertaken, responds with significantly higher participation in the extensive ballot box stuffing case. However this evidence is not always confirmed when limiting the analysis to a setting characterized by a decreasing, rather than an increasing, quality of electoral integrity. This suggests that

\footnotetext{
${ }^{3}$ In particular, we decided to make the extent of fraud clear to the participants since we aim to provide first evidence of voters' behaviour in a clear and clean environment. As in most experimental studies, our study abstracts away from many elements of real life in order to cleanly identify specific effects and motivations. However, in the conclusion we highlight interesting future research questions. Our game can be easily modified to include, for example, the effects of the perception of fraud on turnout or a player whose role is to decide whether to rig the elections or not.

${ }^{4}$ The study of political processes has only recently started to incorporate behavioral economics insights. van Winden (2015), for example, investigates the role of emotions and relationships in political economics. For a survey see Schnellenbach and Schubert (2015).
} 
the timing of (extensive) electoral fraud might play a role in affecting voters' behaviour. The observed differences between the Framing and Neutral treatments suggest that voting behaviour cannot be solely explained by the (in)ability of agents to correctly infer their expected pay-offs when deciding to vote or to abstain. In this paper we provide evidence of behavioural aspects that cannot be disregarded when considering voting in a fraudulent environment.

\section{Related literature}

In spite of its frequent occurrence, fraud has rarely been studied within the theoretical literature on voting. Previous works mainly analyse how different type of electoral malpractices, such as vote buying and electoral violence, affect elections (Collier and Vicente, 2012, Ellman and Wantchekon, 2000). The closest study to our own is provided by Vorobyev (2016), who investigates the mechanism of making participation decisions in the presence of electoral fraud. In his theoretical model electoral fraud is designed as ballot rigging, so that when a voter abstains, their unused ballot may be transformed into a vote for the incumbent with known probability. According to the analysis of Vorobyev (2016), two equilibria exist: abstention, where none of the voters vote and the incumbent always wins, and coordination, where some challenger's supporters vote and the candidate preferred by the majority is likely to win. With respect to this paper, there are a number of differences in the way we set up both the model and the fraud technology, as shown in section 3. In particular, we do not model electoral fraud as stolen votes, but rather consider the number of fake ballots introduced independently from the number of abstaining voters. An important outcome difference is that in our model the probability of the incumbent winning the election monotonously increases with the number of fake ballots. Most importantly, we test our predictions by means of an experiment and provide evidence that voter turnout may increase, rather than decrease, as a consequence of electoral fraud. 
In the empirical literature, electoral fraud has been shown to substantially impact the outcome of the polls (Enikolopov et al., 2013), increasing the probability of the incumbent to win the elections (Collier and Hoeffler, 2009). Drawing on aggregate-level data from different countries, it has been found that electoral fraud decreases participation by either making the outcome less predictable and thus representing an additional cost to voters (Vergne, 2009), or by decreasing the perception of electoral integrity and citizens' trust in elections, finally reducing their propensity to vote (Birch, 2010, Carreras and İrepoğlu Yasemin, 2013, McCann and Dominguez, 1998). Conversely, by using data from a voters' representative survey, Bratton (2008) shows that vote buying has no statistically significant impact on voter turnout, while the threat of violence has a negative effect on it.

However, electoral fraud is inherently difficult to observe and measure, so that it is difficult to study the relationship between electoral fraud and turnout using empirical data. Moreover, the impact of electoral integrity on voter turnout may not be straightforward, since different types of electoral malpractices (threat of violence, coercion, vote buying, etc.) and magnitudes of electoral fraud may lead to different and contrary effects, as well as both complex micro and macro conditions which have to be controlled for in empirical studies (Norris, 2014). These studies are often based on the perception of fairness of elections, an opinion that also depends on people's candidate preference and campaign competitiveness (Wolak, 2014). Our laboratory experiment allows to investigate the effects of electoral fraud in a controlled environment where ceteris paribus analysis is possible, thus overcoming the limitations of previous empirical studies.

The consequences of fraud on voters' participation is unclear also from a behavioural point of view. In the electoral context, the procedure by which the candidate is elected is of extreme importance. In particular, in the social psychology literature, Deutsch (1975) states that "people are more apt to accept decisions and their consequences if they have participated in making them" (p.139): when the electoral process is unfair, in 
the sense that it allows fraudulent interventions to limit people's participation, voters may be more likely to cast a vote for their preferred, but unfairly sabotaged, candidate with respect to a situation when there is no fraud at all. In order to define an election as fair, procedural characteristics are fundamental, as shown by the experiment by Wilking (2011): participants were asked to judge a series of hypothetical scenarios and their opinion about fairness in the elections was largely independent of whether they resided in a democracy or non-democracy, or whether they were politically engaged. Previous research on the effect of procedural injustice in Economics has shown that people are prone to impose a cost, both on themselves and others, to resist procedures that they value as biased (Bolton et al., 2005). Individuals' intrinsic sense of (procedural) fairness, activated by framing the experiment as an election characterized by a fraudulent voting mechanism, will thus act as a motivating force in individual choice behaviour. Whenever procedural injustice affects emotions such as anger, we expect that it can in turn affect turnout (Tarrow, 1998). People may be willing to bear a higher cost of voting in order to take revenge when being treated unfairly in an election. In line with this reasoning, in their recent laboratory experiment, Aimone et al. (2017) show that voters are willing to engage in voting as a form of punishment against candidates who broke their electoral promises, even if they are indifferent with respect to the electoral outcome. However, it is also possible that voters, when facing electoral fraud, may be rather less likely to cast a vote for their preferred party, shying away from the unfairness of the electoral procedure. Our study allows to examine whether and how voters react to the procedural unfairness of elections, when the fraudulent intervention is made common knowledge. In this paper we provide first experimental evidence of the effects of electoral fraud on voter turnout in a very simple framework. In the experiment we intentionally analyse voters' behaviour in an environment where the level of fraud is known, certain and exogenously imposed. This was done in order to allow us to investigate the relationships hypothesised in the theoretical model, while abstracting from other factors which may 
also be at work in the broader social setting namely, for example, the ambiguity of electoral fraud and the relevance of the candidate's intentions when applying ballot box stuffing. We thus acknowledge that future research is needed to shed light on the role of these aspects in influencing turnout in a system characterized by electoral fraud.

In the experiment we compare a Neutral Treatment with a Framing one, where the election environment is explicitly stated and the fraudulent intervention in the electoral process is made common knowledge. Given the complexity of the real world, especially in the political context, we aim to analyse whether framing the experiment as a fraudulent election makes people react differently with respect to an identical situation, where actions and payoffs are expressed in neutral terms.

The role of differently framing the elections on voter turnout has rarely been systematically tested. Previous researchers have studied how media frames affect voter turnout and vote choice (Butler and Marchal, 2007, Schuck et al., 2013, 2014, Valentino et al., 2001), underlying the role of both transparency about the redistributive consequences of individual' votes (Paetzel et al., 2017) and source credibility (Druckman, 2001) in making framing successful. Our paper extends this literature by testing for the existence and consequences of the framing effect of ballot rigging on voting behaviour within a laboratory experiment. As suggested by Druckman (2004), investigating in which contexts framing effects occur allows for a deeper understanding of the applications of the rationality assumptions.

Previous researchers have investigated voter turnout in the laboratory, under many different institutions: Schram and Sonnemans (1996), Grosser et al. (2005), Grosser and Schram (2010) focus on participation games and coordination problems such as the volunteer's dilemma while Houser et al. (2011) and Houser and Stratmann (2008) investigate the effects of campaign advertising on voting. ${ }^{5}$ One of the most influential experimental papers on voter turnout is provided by Levine and Palfrey (2007), who

\footnotetext{
${ }^{5}$ Palfrey (2009)) provides a survey of experimental studies of voting behaviour.
} 
investigate voter turnout by addressing comparative statics questions about the effect of the electorate size, relative party size, and voting cost on subjects' decision to vote. Their results support their theoretical predictions with the exception that turnout probabilities are higher than those predicted when considering larger electorates (i.e. with 27 and 51 voters). The design of our experiment allows us not only to compare our results with those obtained by Levine and Palfrey (2007) but, more importantly, to investigate the effect of introducing fraud into the electoral system on the voting behaviour of the electorate.

\section{The model}

We define electoral fraud as "the corruption of the process by which votes are cast and counted", as suggested by Minnite and Callahan (2003) and, similarly, by Lehoucq (2002). In the present study we apply ballot-box stuffing type of fraud. However, it is worth emphasising that qualitatively similar theoretical results are obtained when asymmetries in costs are introduced between the supporters of the two groups.

In our model we include electoral fraud in the framework developed by Levine and Palfrey (2007). There are $N$ voters who can choose to vote or to abstain. They support one of the two candidates: the Incumbent (I) or the Challenger (C) with $N_{I}<N_{C}$, so that supporters of the Incumbent are in the minority. The sizes of the two groups are common knowledge. Voting is assumed to be costly and every voter $i$ knows their own $\operatorname{cost} c_{i}$. They also know the single-peaked distribution function $f(c)$ from which the voting costs of the other voters are independently drawn. The candidate who receives more votes wins the elections and ties are broken by a fair coin toss. If candidate $I$ wins, all voters supporting him receive a reward $H$ and all voters supporting candidate $C$ receive a reward $L$, with $L<H$, while the opposite happens when candidate $C$ wins. The size of the rewards is common knowledge.

The Incumbent can interfere with the elections by introducing fake ballots. The strategy 
of the Incumbent is defined as the (integer) number $\delta \in[0, \Delta]$ of fake ballots which are placed in the polling box. The electoral fraud applied by the Incumbent is supposed to be costly. Interventions must increase their probability of winning the election, given the electoral rule in force. Let $\Phi(\delta)$ be the convex cost function of the fraud. Also, let $n_{I}^{*}$ be the expected number of the Incumbent's supporters who vote in equilibrium and $n_{C}^{*}$ be the expected number of the Challenger's supporters who vote in equilibrium.

We define the expected plurality EP as the difference between the expected number of votes in favour of the Incumbent and in favour of the Challenger - $E P(\delta)=\delta+n_{I}(\delta)-$ $n_{C}(\delta)$. The falsifier's problem would be ${ }^{6}$ :

$$
\begin{gathered}
\max _{\delta}-(E P(\delta)-\mathcal{M})^{2} \\
\text { s.t. } \Phi(\delta) \leq \mathcal{B}
\end{gathered}
$$

where $\mathcal{M}$ is the difference in votes that the Incumbent wants to achieve in equilibrium. Thus, $\mathcal{M}=1$ describes a situation where the Incumbent is only interested in winning the elections, whereas $\mathcal{M}>1$ corresponds to a situation where a larger expected margin of victory is required. Though theory suggests that in a binary election a candidate must only be interested in getting more votes than the opponent, there is widespread evidence that Incumbents apply wider manipulations to win elections with a larger margin. Benefits of excessive fraud during the elections can be of various types, such as discouraging opponents from joining or supporting rival parties, from voting, or from participating in the competition in other ways or, alternatively, it may motivate supporters to participate more actively (Simpser, 2013). $\mathcal{B}$ is the exogenously given budget of the falsifying Incumbent.

\footnotetext{
${ }^{6} \mathrm{An}$ alternative formulation where the win probability is directly incorporated into the Incumbent's preferences would be the following: $\max _{\delta} R \cdot \operatorname{prob}\left[n_{I}^{*}(\delta)=n_{C}^{*}(\delta)+\mathcal{M}\right]-\Phi(\delta)$, where $R$ is the benefit associated with winning and $\Phi(\delta)$ is the cost function of the fraud.
} 
Players move simultaneously in the above described game. While in turnout models simultaneity is considered a natural modelling approach for voters, the actions of the Incumbent require additional clarification. An alternative view would be to assume that the Incumbent can actually monitor the process of the election (e.g. by applying exit polls) or even falsify the electoral results after the vote count. Differently, we assume simultaneity of choices believing that the fraudulent interventions on behalf of the Incumbent need to be planned and designed in advance and thus cannot be considered a "last minute" response to negative developments on the election day.

In the following, we look for group symmetric equilibria of the voting game, which are known to be in cut-point strategies. A cut-point strategy for voter $i$ specifies a cost level $c_{i}^{*}$ such that voter $i$ abstains if and only if $c_{i}>c_{i}^{*}$. This implies an aggregating voting probability for each group, $\left(p_{C}^{*}, p_{I}^{*}\right)$ given by:

$$
\begin{aligned}
& p_{C}^{*}=\int_{-\infty}^{c_{C}^{*}} f(c) d c=F\left(c_{C}^{*}\right) \\
& p_{I}^{*}=\int_{-\infty}^{c_{I}^{*}} f(c) d c=F\left(c_{I}^{*}\right)
\end{aligned}
$$

Given that in equilibrium every voter in the group follows the same rule, this means that a voter with a voting cost exactly equal to $c^{*}$ must be indifferent between voting and abstaining. It is easy to demonstrate that these indifference conditions are given by the following equations:

$$
\begin{gathered}
c_{I}^{*}=\frac{H-L}{2}\left(\operatorname{prob}\left[n_{I}^{i}+\delta+1=n_{C}\right]+\operatorname{prob}\left[n_{I}^{i}+\delta=n_{C}\right]\right) \\
c_{C}^{*}=\frac{H-L}{2}\left(\operatorname{prob}\left[n_{C}^{j}+1=n_{I}+\delta\right]+\operatorname{prob}\left[n_{C}^{j}=n_{I}+\delta\right]\right)
\end{gathered}
$$

Superscript 'i' ('j') indicates that the number of those who voted for the Incumbent 
(Challenger) is $n_{I}\left(n_{C}\right)$ excluding voter 'i' ('j’).

Given the preferences of the falsifier, the equilibrium of the game is characterised by the following conditions:

$$
\begin{gathered}
c_{I}^{*}=\frac{H-L}{2} \pi_{I}^{*}\left(p_{I}^{*}, p_{C}^{*}, \delta^{*}, N_{I}, N_{C}\right) \\
c_{C}^{*}=\frac{H-L}{2} \pi_{C}^{*}\left(p_{I}^{*}, p_{C}^{*}, \delta^{*}, N_{I}, N_{C}\right) \\
\arg \max _{\delta}-\left(\delta^{*}+p_{I}^{*}(\delta) N_{I}-p_{C}^{*}\left(\delta^{*}\right) N_{C}-\mathcal{M}\right)^{2} \\
\Phi\left(\delta^{*}\right) \leq \mathcal{B}
\end{gathered}
$$

where $\pi_{I}$ and $\pi_{C}$ are the pivot probabilities and have the following representation:

$$
\begin{aligned}
& \pi_{I}^{*}= \sum_{k=0}^{N_{I}-1}\left(\begin{array}{c}
N_{I}-1 \\
k
\end{array}\right)\left(\begin{array}{c}
N_{C} \\
k+\delta
\end{array}\right)\left(F\left(c_{I}^{*}\right)\right)^{k}\left(1-F\left(c_{I}^{*}\right)\right)^{N_{I}-1-k} \\
& \times\left(F\left(c_{C}^{*}\right)\right)^{k+\delta}\left(1-F\left(c_{C}^{*}\right)\right)^{N_{C}-k-\delta}+\sum_{k=0}^{N_{I}-1}\left(\begin{array}{c}
N_{I}-1 \\
k
\end{array}\right)\left(\begin{array}{c}
N_{C} \\
k+\delta+1
\end{array}\right)\left(F\left(c_{I}^{*}\right)\right)^{k} \times \\
&\left(1-F\left(c_{I}^{*}\right)\right)^{N_{I}-1-k}\left(F\left(c_{C}^{*}\right)\right)^{k+\delta+1}\left(1-F\left(c_{C}^{*}\right)\right)^{N_{C}-k-1-\delta} \\
& \pi_{C}^{*}=\sum_{k=0}^{N_{I}}\left(\begin{array}{c}
N_{I} \\
k
\end{array}\right)\left(\begin{array}{c}
N_{C}-1 \\
k+\delta
\end{array}\right)\left(F\left(c_{I}^{*}\right)\right)^{k}\left(1-F\left(c_{I}^{*}\right)\right)^{N_{I}-k} \times \\
&\left(F\left(c_{C}^{*}\right)\right)^{k+\delta}\left(1-F\left(c_{C}^{*}\right)\right)^{N_{C}-k-\delta-1}+\sum_{k=0}^{N_{I}}\left(\begin{array}{c}
N_{I} \\
k
\end{array}\right)\left(\begin{array}{c}
N_{C}-1 \\
k+\delta-1
\end{array}\right) \times \\
&\left(F\left(c_{I}^{*}\right)\right)^{k}\left(1-F\left(c_{I}^{*}\right)\right)^{N_{I}-k}\left(F\left(c_{C}^{*}\right)\right)^{k+\delta-1}\left(1-F\left(c_{C}^{*}\right)\right)^{N_{C}-k-\delta}
\end{aligned}
$$


We do not make any explicit assumptions about the cost function $\Phi(\delta)$ and we are not going to solve the Incumbent's problem explicitly. As it will be made clear below, in the current framework fraud monotonically increases the expected plurality (or winning probability) in favour of the Incumbent, hence limited fraud can be rationalized only by assuming that the falsifier is cost constrained. Since we are interested in the reaction of the electorate to different levels of electoral fraud, we assume that the parameters of the Incumbent's objective function and budget constraint are such that he can introduce a sufficient level of fraud in the election to win it (in expectation). When deriving the equilibrium of the voting game, we will thus focus only on the strategies of the voters, who are acting simultaneously. In the general case, the exogenously given absolute margin of victory $\mathcal{M}$ derives the equilibrium of the game, which determines the optimal fraud level endogenously.

\subsection{Predictions}

Numerical estimation techniques are applied to obtain the exact predictions for the turnout rate in the game. Given that we do not have a falsifier as a subject in the lab, we fix the fraud level exogenously.

We assume that voting costs are sufficiently high for some voters, so that abstention is their dominant strategy (Palfrey and Rosenthal, 1985), and equal to zero with positive probability for other voters, so that for them voting will be a weakly dominant strategy, irrespective of the number of fake ballots introduced. This, along with the assumption of a single-peaked cost distribution, ensures a unique group-symmetric equilibrium in our setup.

Table 1 presents the results of our numerical estimations of the equilibria. In Figure 1, in order to verify the robustness of our predictions, we provide a graphical view of our numerical estimations for different electorate sizes, while keeping the Incumbent's relative support constant (Left Panel), as well as for a range of support for the Incumbent, 
keeping the total number of voters fixed (Right Panel).

\begin{tabular}{|c|c|c|c|c|c|c|}
\hline \multirow{4}{*}{$\begin{array}{l}\text { Incumbent group size } \\
\text { Challenger group size }\end{array}$} & 9 & \multicolumn{5}{|c|}{ (fraud in favour of Incumbent) } \\
\hline & 18 & & & & & \\
\hline & \multicolumn{6}{|c|}{ Number of fake ballots } \\
\hline & 0 & 1 & 2 & 3 & 4 & 5 \\
\hline Group turnout probability (Incumbent) & 0.27 & 0.29 & 0.30 & 0.30 & 0.25 & 0.11 \\
\hline Group turnout probability (challenger) & 0.23 & 0.26 & 0.29 & 0.30 & 0.28 & 0.19 \\
\hline Expected Turnout (Incumbent group) & 2.43 & 2.61 & 2.71 & 2.66 & 2.27 & 0.97 \\
\hline Expected Turnout (challenger group) & 4.10 & 4.77 & 5.25 & 5.43 & 5.08 & 3.38 \\
\hline Expected Total turnout & 6.53 & 7.38 & 7.96 & 8.09 & 7.35 & 4.35 \\
\hline Expected Plurality & -1.67 & -1.15 & -0.53 & 0.23 & 1.20 & 2.59 \\
\hline Pivot Probability & 0.40 & 0.44 & 0.47 & 0.47 & 0.43 & 0.26 \\
\hline Probability of Incumbent winning & 0.23 & 0.32 & 0.42 & 0.54 & 0.70 & 0.91 \\
\hline Total turnout rate & 0.24 & 0.27 & 0.29 & 0.30 & 0.27 & 0.16 \\
\hline
\end{tabular}

Table 1: Theoretical predictions.

Figure 1: Results of our numerical estimations
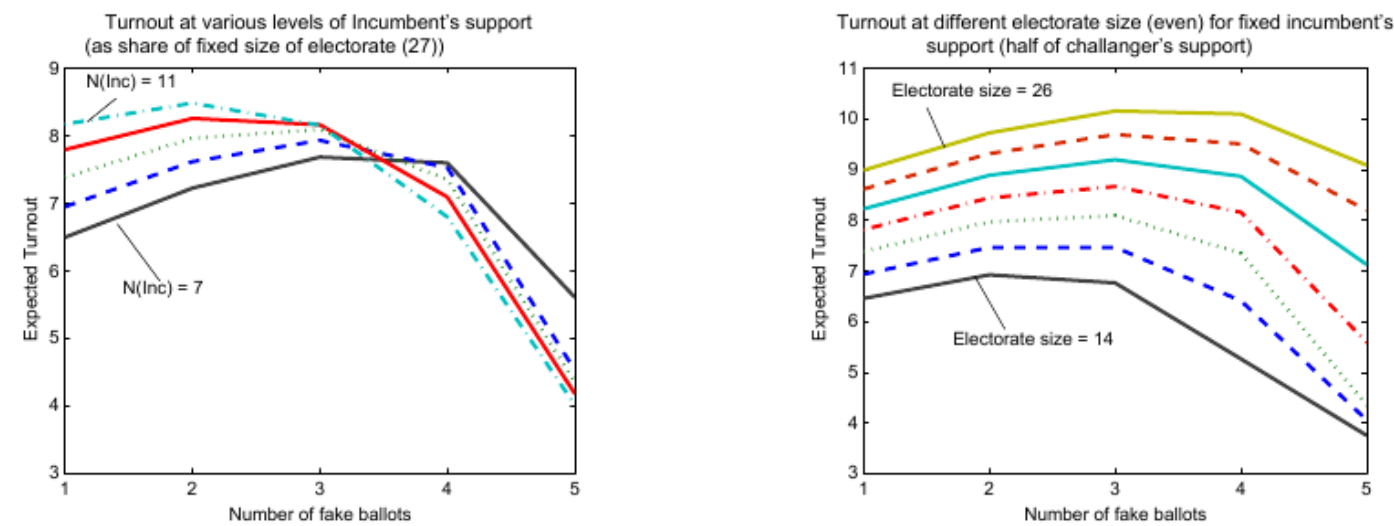

As suggested by the results of our numerical estimations, electoral fraud increases turnout rate when it is limited and decreases it when the level of fraud is high. Differently to Vorobyev (2016), where the participation of the Incumbent's supporters decreases with higher probability of ballot rigging, our model predicts that a low level of electoral fraud positively affects participation of both the majority and the minority party. The intuition behind such a difference depends on the electoral fraud's techno- 
logy: while in Vorobyev (2016) it is modelled as the probability that the abstainers' vote will be stolen, in our framework it is designed as the number of fake ballots added to the pool, so that the probability of tied elections increases with a low level of fraud. In its turn, the higher the probability of a tied election, the lower the incentive to free ride in the larger group and the higher the incentive to vote for the minority, since they have higher a chance of casting a pivotal vote. This statement can easily be verified by looking at the change in pivot probabilities. Strategic motives to vote diminish at a high rate once the fraud goes beyond the level that guarantees the expected victory in binary elections.

\subsection{Testable hypothesis}

Based on the predictions of the theoretical model we formulated the following hypotheses:

Hypothesis 1. In the Baseline condition a higher turnout is observed for the underdog candidate, as a manifestation of the classic free-riding problem in the larger group.

Hypothesis 2. The relationship between the extent of the fraudulent intervention and the turnout rate has an inverted U-shaped pattern. Limited fraud increases turnout while higher levels of fraud decrease it beyond the level observed in the Baseline condition without fraud.

Hypothesis 2a. The turnout patterns described in Hypothesis 2 are observed both in the minority and majority groups.

In addition to these two purely strategic hypotheses derived from the model, we have an additional behavioural hypothesis: 
Hypothesis 3. Framing the experiment as an election with vote rigging increases voter turnout with respect to a neutral environment, because of the the majority's reaction to procedural injustice.

Deviations from equilibrium in the Framing treatment can be attributed to three main motives. The framing treatment might i) induce individuals to hold mistaken beliefs about their probability of being pivotal, ii) make them choose a strategy which is inconsistent with their beliefs, namely a reaction to procedural unjustice or, finally, it might iii) create an experimenter demand effect, when individuals do not want to appear to be passively accepting vote rigging in the eyes of the experimenter. ${ }^{7}$

With respect to point i) and ii), Duffy and Tavits (2008) experimentally investigate whether there is a direct correlation between the strength of an individual's belief to be pivotal and their likelihood to vote. In their abstract experiment, they provide evidence that participants are more likely to turnout if they believe their vote to be pivotal, and that they systematically overestimate this probability. Their results suggest that holding mistaken beliefs about their own pivotality might be a possible explanation for individuals' deviations from equilibrium, rather than individuals' failure to best respond to those beliefs. In our experimental setting we did not include a belief elicitation phase so these two effects cannot be clearly disentangled. However, if beliefs about others' voting behaviour are influenced differently in the Neutral vs. Framing treatment, we should expect this phenomenon to affect our results both with low and high levels of fraud, meaning that differences in voter turnout between the Neutral and Framing treatment should be observed independently of the strength of the ballot box stuffing. We can thus provide indirect evidence to test for this effect by analysing the experimental data.

\footnotetext{
${ }^{7}$ We thank an anonymous referee for providing us with the intuition on the experimenter demand effect and on the possible role of beliefs.
} 
With respect to point iii), even if we cannot a priori exclude that the experimenter demand effect plays a role in explaining our results, previous evidence in the literature about bribing and dishonesty provides interesting insights into this concern. In our experiment, individuals in the Framing treatment might not want to be a voter who passively accepts vote rigging. Abbink and Hennig-Schmidt (2006) explicitly tested the role of loaded versus neutral instructions in a bribery experiment, a context where participants might not want to appear to the experimenter as those who accept bribery. The authors found that even if the framing treatment had a lower bribery rate and bribery acceptance rate, the difference was too small to be statistically significant. In Fischbacher and Föllmi-Heusi (2013), the authors experimentally test the emergence of dishonesty by means of the die under the cup paradigm. They found no effect of increasing anonymity on the lying pattern of individuals, suggesting that reputational concern with respect to the experimenter in the moral sphere might not be a big concern.

Nevertheless, we acknowledge that further research is needed to clearly and cleanly disentangle the above described forces, for example by increasing the social distance between the experimenter and the subjects (i.e. increasing anonymity) in order to investigate the experimenter demand effect, this would however, as a drawback, reduce control.

\section{Experimental design}

Our experiment mirrors the game discussed in the theoretical model, with few differences.

In the Baseline condition, at the beginning of each period, each participant is informed whether he was randomly assigned to group ALPHA or to group BETA ${ }^{8}$ Group A is composed of 9 participants while group B is composed of 18 participants. The two sizes

\footnotetext{
${ }^{8}$ In the following we refer to group A for group ALPHA and to group B for Group BETA. Random reassignment of subjects to groups A or B was intended to minimize repeated-game effects.
} 
were common knowledge to all participants. ${ }^{9}$ Individuals are asked in each round to choose $\mathrm{X}$ or $\mathrm{Y}$. The voting cost is referred to as a $\mathrm{Y}$ bonus and is added to a participant's earnings if that participant chooses option $\mathrm{Y}$ instead of choosing option $\mathrm{X}$ in a round. Therefore, the voting cost is implemented as an opportunity cost. Bonuses are randomly redrawn in every round, independently for each subject, and subjects are told their own Y bonus before making any decision. We thus assume incomplete information about voters' heterogeneous voting costs. If a participant chooses X, that participant does not receive their $\mathrm{Y}$ bonus for that round.

Payoffs in each round are determined as follows: if more members of $\mathrm{A}(\mathrm{B})$ choose $\mathrm{X}$ than members of $\mathrm{B}(\mathrm{A})$, then each member of $\mathrm{A}(\mathrm{B})$ receives 105 and each member of group $\mathrm{B}(\mathrm{A})$ receives 5 . In the case of a tie, each member of each group receives 55 .

In order to test the effect of electoral fraud on individuals' voting behaviour, we implement the Fraud I and Fraud II conditions. In Fraud I and Fraud II everything is the same as in the Baseline condition, with the only exception being that now respectively 2 and 5 fake ballots are automatically added to the minority group.

In each experimental session, participants play the the Baseline game for 50 rounds, while both Fraud I and Fraud II games are repeated for 25 rounds.

In our main treatment, the Neutral treatment, in the instructions we never refer to elections or voting or ballot rigging, labels are abstract. ${ }^{10}$

Differently than in our theoretical model, in the experiment we decided not to include a subject playing the role of the Incumbent choosing the optimal level of fraud for three main reasons. First, in the theoretical model, the Incumbent and their preferences are important to understand why the fraud can be limited in size, so that its existence has no impact on our predictions on voter turnout. Second, including such a role in the experiment would have unnecessarily complicated our design, adding an additional level

\footnotetext{
${ }^{9}$ We decided to choose these group sizes for the A and B groups in order to compare experimental data with clear-cut theoretical predictions about voting behaviour. When theoretical predictions are not matched, it is less probable that this will happen in a more favourable situation.

${ }^{10}$ For the English version of the instructions (originally in Italian) see the on-line Appendix A.
} 
of procedural unfairness. If anything, the presence of an Incumbent would strengthen our results. Third, since to the best of our knowledge we are the first to examine the effect of fraudulent elections on voter turnout in a clean and simple way, an Incumbent would have made our analysis closer to the real world but would have also made our results on turnout more difficult to interpret: its inclusion would have brought about new questions such as the Incumbent's expectations of voter behaviour and vice-versa, and distributional considerations of the Incumbents' and their supporters' payoffs. We thus decided to leave this dimension to further research.

\subsection{Experimental Procedures}

The experiment was programmed using zTree (Fischbacher, 2007). We conducted 6 sessions of the Neutral Treatment at the EELAB experimental laboratory of the University of Milano-Bicocca, involving 162 participants in total.

Since we think that the natural field setting in which our results would be most applicable are the ones more likely to involve a decreasing quality of elections, with an electoral system which progressively evolves through a situation of electoral fraud, 4 Order sessions, characterized by a decreasing quality of elections (Baseline - Fraud I Fraud II), were run from October 2014 to January 2015. To check for the robustness of our results, we also investigated the effect of electoral fraud on voter turnout when considering elections characterized by an increasing integrity: 2 Reverse Order sessions were run in December 2015, so that participants played the Fraud II condition first, then the Fraud I and, finally, the Baseline condition.

Subjects were recruited from the undergraduate population of the University of MilanoBicocca, via ORSEE software (Greiner, 2004). No subject participated in more than one session of this experiment.

Once in the laboratory, each participant was randomly assigned to one visually isolated computer terminal. The instructions for the first part were then read aloud and par- 
ticipants could read them on their screen. Individuals were asked to answer a set of control questions on the screen.

Instructions about each of the following parts were made to appear on the subjects' screen and read aloud only after the completion of the previous instructions.

A test for risk aversion (Holt and Laury, 2002) was implemented as the last task.

At the end of each session, the pay-off of all rounds was added up and the sum was converted into Euros. Before proceeding with payment to the subjects, we asked participants to fill out a demographic form in order to collect information about their age and gender. The duration of each session was about 60 minutes and the average payment was 14 Euros.

\section{Results}

We study the impact of fraudulent electoral intervention by taking into account the fact that participants' choices may be dependent upon previous periods in the same session. In particular, when comparing voting behaviour between and within treatments we report the results, respectively, from a two-sample Wilcoxon rank-sum (Mann-Whitney), by averaging the data within a session and treating each session as a single observation, and from a Wilcoxon signed-rank test, by pairing the observed frequency of voting of the majority and minority group in each session. ${ }^{11}$

\section{$5.1 \quad$ Neutral Treatment}

In the following we report the results of the Order sessions, of the Reverse Order ones and of a combination of both of them. ${ }^{12}$ A more detailed and precise analysis is conducted thereafter, where a series of regression models are used to analyse turnout behaviour at

\footnotetext{
${ }^{11}$ In the following we refer to MW for the Mann-Whitney test and to WSR for the Wilcoxon signedrank test.

${ }^{12}$ Since the Reverse Order sessions were implemented as a robustness check, it is important to note that the lower number of (independent) observations with respect to the Order sessions calls for a very large effect size to reach an acceptable statistical power.
} 
the individual level.

We initially consider the Baseline condition without any fraud intervention: we compare the observed results with our theoretical predictions and with those obtained in previous studies. We then assess the impact of the fraudulent intervention on turnout, in order to estimate to what extent voters are behaving strategically.

We start our analysis by considering voter turnout in the Baseline condition. Table 2 shows the aggregate turnout rates for the Baseline condition and compares them with our theoretical equilibria.

\begin{tabular}{c|c|c|c}
\hline & Experimental Results & $\begin{array}{c}\text { Neutral } \\
\text { Treatment }\end{array}$ & $\begin{array}{c}\text { Theoretical } \\
\text { Equilibrium }\end{array}$ \\
\hline \multirow{4}{*}{ Majority } & Order & 0.323 & \\
& Reverse Order & $0.018)$ & \\
& & 0.308 & 0.228 \\
& Both & $0.007)$ & \\
& \multirow{4}{*}{ Minority } & $(0.012)$ & \\
& \multirow{2}{*}{ Reverder } & 0.367 & \\
& & $0.025)$ & \\
& \multirow{3}{*}{ Both } & 0.319 & \multirow{2}{*}{0.270} \\
& & $0.026)$ & \\
& & 0.351 & \\
\hline
\end{tabular}

Table 2: Turnout rates under the Baseline condition in the Neutral treatment (Standard error in parentheses).

According to our theoretical model, we should observe voter turnout to be equal to 0.228 and 0.270 , in the majority and minority group, respectively. Participants in the experiment voted with a significantly higher frequency than theoretically hypothesised, independently of the order of the sessions (one-sample WSR: $\mathrm{p}<0.10$ ). Considerable over-voting was also observed in Levine and Palfrey (2007), when considering treatments with large electorates (i.e. 27 and 51). One of the central results consistently predicted in strategic costly voting games is that higher turnout is expected among the underdog candidate's supporters. This is due to the manifestation of the classic free riding incentives in the larger group, which in turn makes voting for the representatives 
of the smaller group more rewarding.

A Wilcoxon signed-rank (WSR) provides evidence that the overall average turnout rate (50 rounds) is significantly higher for the minority group than for the majority group (Order sessions: $p=0.0^{72}$, one-sided). ${ }^{13}$ The same results hold when analysing both the Order and Reverse Order sessions together ( $p=0.06$, one-sided), but fails to reach significance in the Reverse Order sessions. Result 1 states our main findings in the Baseline condition, at the aggregate level.

Result 1. In the Neutral treatment without electoral fraud, the turnout rate is higher in the minority group than in the majority group, providing evidence that Hypothesis 1 cannot be rejected.

In the following, we analyse voters' response to electoral fraud, which is the main objective of our study. According to our theoretical predictions, both for the majority and minority groups, voting should increase when 2 fake ballots are introduced (Fraud I) while it should fall to a lower level than the Baseline condition when 5 fake ballots are added to the minority group (Fraud II).

Figure 2 graphs the voter turnout rate observed in the Baseline, Fraud I and Fraud II conditions in the Neutral treatment.

We first investigate whether the differences in turnout between the Baseline and Fraud I voting conditions are statistically significant. Our tests provide evidence that a low level of fraud significantly increases turnout in the Neutral treatment (WSR, Order sessions: $p=0.068)$. The same results hold when analysing both the Order and Reverse Order sessions together (WSR, $p=0.028$ ), but fails to reach significance in the Reverse Order sessions (WSR: $p=0.180$ ).

\footnotetext{
${ }^{13}$ All statistical tests reported are two samples and two-sided unless differently specified. When we have clear, explicit and theory-driven predictions about voters' behaviour in the different treatments we used one-sided tests.
} 
Figure 2: Voter turnout across periods in the Baseline, Fraud I and Fraud II parts in the Neutral treatment.
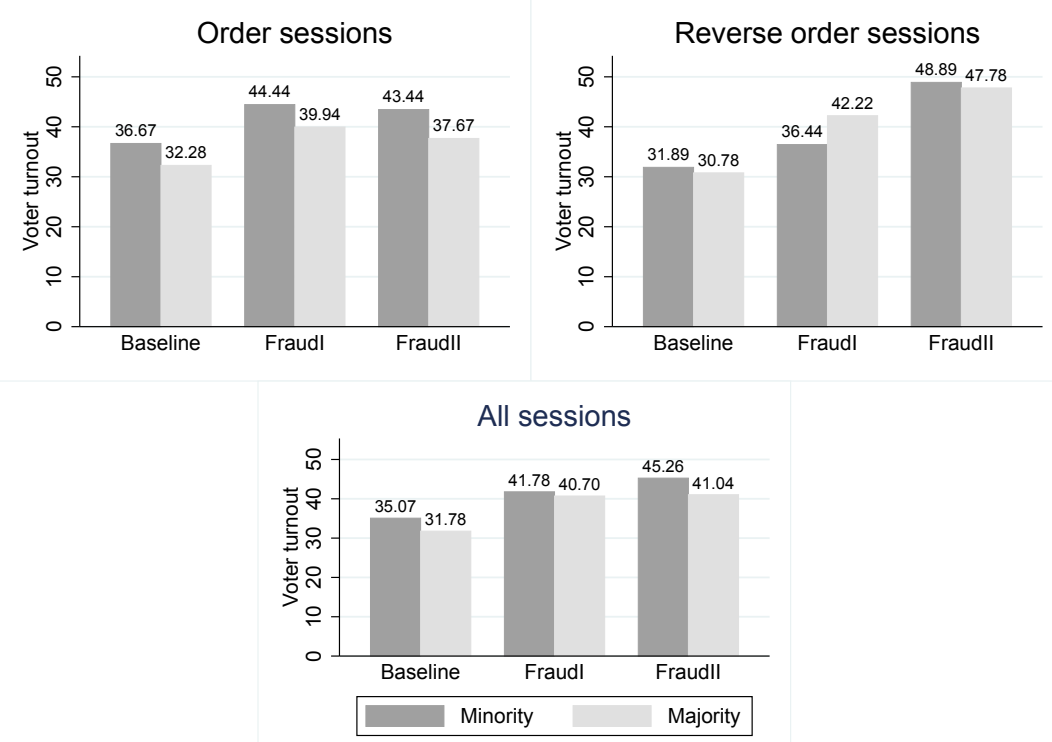

Average voter turnout by group and level of electoral fraud in the Neutral treatment.

More specifically, our findings reject the null hypothesis when using data from all rounds when considering the majority group (Order sessions: $p=0.068$ ) but not the minority group (Order sessions: $p=0.143) .{ }^{14}$

Our second result summarizes our findings.

Result 2. With respect to the Baseline condition, in the Neutral treatment, total voter turnout significantly increases in Fraud I.

Result 3 states our main finding with respect to the introduction of a high level of ballot box stuffing in the elections, in Fraud II.

\footnotetext{
${ }^{14}$ When considering all sessions together, we observe that turnout significantly increases from Baseline to Fraud I for both the minority and majority group (WSR, Order \& Reverse order sessions, majority: $p=0.028$; minority: $p=0.046)$.
} 
Result 3. In the Neutral treatment, voter turnout in Fraud II is significantly lower than in Fraud I, only when considering an electoral system characterized by a decreasing quality of elections. Moreover, participation in the elections is still higher than in the Baseline.

Our results are only partially consistent with our Hypothesis 2 and Hypothesis 2a. While when increasing the fraudulent intervention in favour of the minority group to five ballots the total voter turnout in the Neutral treatment is lower than when two fake ballots are added (WSR test, Order sessions: $p=0.068$ ), we still observe that participants overvote with respect to our theoretical predictions: participation in the elections is still higher than in the Baseline. Moreover, the same result does not hold if we also include the Reverse Order sessions in the analysis, since voter turnout corresponds to 41.07 in Fraud I and to 42.44 in Fraud II, showing that this evidence is not robust when reversing the order of the games. More specifically, while in the Baseline condition there are no differences among the Order and Reverse Order sessions, when considering electoral fraud we observe that voting behaviour does not exactly follow the same pattern, independently of the order. This might be due to the fact that, even in the absence of any framing, the inclusion of electoral fraud could already be perceived as a salient phenomenon, that differently affects behaviour depending on whether it is present from the beginning or not. We thus further investigate the role of the order of the sessions by means of a regression analysis, which enables us to capture the individual level of heterogeneity that characterizes our data.

In Table 3 we report the marginal effects of a series of regression models to test our hypotheses, while additional robustness checks are provided in the Appendix. In Table 3 we include all the experimental sessions in our analysis. ${ }^{15}$

\footnotetext{
${ }^{15}$ In the Appendix B we restrict our analysis to the Order sessions, in particular for the fixed effects models, since in these specifications the time-invariant variables are automatically omitted and we thus cannot include the variable "Order" as a control.
} 


\begin{tabular}{|c|c|c|c|c|}
\hline & (1) & (2) & (3) & (4) \\
\hline FraudI & $\begin{array}{c}0.08995^{* * *} \\
(0.01104)\end{array}$ & $\begin{array}{c}0.09265^{* * *} \\
(0.01567)\end{array}$ & $\begin{array}{c}0.08881^{* * *} \\
(0.01123)\end{array}$ & $\begin{array}{c}0.08898^{* * *} \\
(0.01559)\end{array}$ \\
\hline FraudII & $\begin{array}{c}0.11122^{* * *} \\
(0.01548)\end{array}$ & $\begin{array}{c}0.12899^{* * * *} \\
(0.02333)\end{array}$ & $\begin{array}{c}0.11012^{* * * *} \\
(0.01528)\end{array}$ & $\begin{array}{c}0.12448^{* * *} \\
(0.02249)\end{array}$ \\
\hline Majority & $\begin{array}{c}-0.03301^{* *} \\
(0.01505)\end{array}$ & $\begin{array}{l}-0.02526 \\
(0.01919)\end{array}$ & $\begin{array}{c}-0.03517^{* *} \\
(0.01514)\end{array}$ & $\begin{array}{l}-0.02937 \\
(0.01995)\end{array}$ \\
\hline Voting cost & $\begin{array}{c}-0.01738^{* * *} \\
(0.00048)\end{array}$ & $\begin{array}{c}-0.01738^{* * *} \\
(0.00048)\end{array}$ & $\begin{array}{c}-0.01538^{* * *} \\
(0.00030)\end{array}$ & $\begin{array}{c}-0.01538^{* * *} \\
(0.00030)\end{array}$ \\
\hline Experience & $\begin{array}{l}-0.00117 \\
(0.00139)\end{array}$ & $\begin{array}{l}-0.00108 \\
(0.00138)\end{array}$ & $\begin{array}{l}-0.00106 \\
(0.00137)\end{array}$ & $\begin{array}{l}-0.00099 \\
(0.00137)\end{array}$ \\
\hline Electoral victories & $\begin{array}{c}0.00072 \\
(0.00234)\end{array}$ & $\begin{array}{c}0.00056 \\
(0.00233)\end{array}$ & $\begin{array}{c}0.00047 \\
(0.00233)\end{array}$ & $\begin{array}{c}0.00035 \\
(0.00232)\end{array}$ \\
\hline FraudI*Majority & & $\begin{array}{l}-0.00403 \\
(0.01994)\end{array}$ & & $\begin{array}{l}-0.00028 \\
(0.02063)\end{array}$ \\
\hline FraudII*Majority & & $\begin{array}{l}-0.02692 \\
(0.02876)\end{array}$ & & $\begin{array}{l}-0.02207 \\
(0.02895)\end{array}$ \\
\hline Risk Aversion & & & $\begin{array}{c}0.00016 \\
(0.00603)\end{array}$ & $\begin{array}{c}0.00017 \\
(0.00604)\end{array}$ \\
\hline Mean of type & & & $\begin{array}{c}-0.45545^{* *} \\
(0.22307)\end{array}$ & $\begin{array}{c}-0.45312^{* *} \\
(0.22259)\end{array}$ \\
\hline Mean of voting cost & & & $\begin{array}{l}0.01110^{*} \\
(0.00608)\end{array}$ & $\begin{array}{l}0.01107^{*} \\
(0.00608)\end{array}$ \\
\hline Mean of electoral victories & & & $\begin{array}{c}0.01204^{* * *} \\
(0.00445)\end{array}$ & $\begin{array}{c}0.01209^{* * *} \\
(0.00445)\end{array}$ \\
\hline Order & & & $\begin{array}{l}-0.03856 \\
(0.02338)\end{array}$ & $\begin{array}{l}-0.03840 \\
(0.02338)\end{array}$ \\
\hline Observations & 16200 & 16200 & 16200 & 16200 \\
\hline (Pseudo) R2 & 0.3430 & 0.3431 & 0.3059 & 0.3060 \\
\hline Chi-squared or F & 268.62 & 224.21 & 642.68 & 775.14 \\
\hline Prob $>$ chi $2 / F$ & 0.000 & 0.000 & 0.000 & 0.000 \\
\hline
\end{tabular}

Table 3: Regression table, Neutral Treatment. Fixed Effects Linear regression model for panel data: (1) and (2). Correlated Random Effects Probit model: (3) and (4). In all models errors are clustered at the individual level.

In all models, the dependent variable is Vote, a dummy variable which takes value one when the participant votes and zero when the participant decides to abstain. First, in models (1) and (2), we present the results of a linear model for panel data with fixed effects and clusters at the level of the individual to control for the autocorrelation.

In models (3) and (4) we present the results of the Correlated Random Effects (CRE) model first proposed by Mundlak (1978), combining the advantages of both fixed and 
random-effects models. In particular, we also include the mean of time-dependent variables as independent variables, identified as Mean of voting cost, Mean of type and Mean of electoral victories. Moreover, in order to drop the serial independence assumption, we also cluster the standard errors at the individual level to make our inference robust to autocorrelation.

Our explanatory variables are the following. Neutral Treatment is equal to one for the Neutral treatment and zero otherwise while FraudI and FraudII are equal to one when participants experience the corresponding level of fraudulent intervention and zero otherwise: the omitted dummy variable is the Baseline condition thus the coefficients have to be considered with respect to this condition. Majority is equal to one if the participant is a member of the majority group and zero otherwise and Voting cost is a categorical variable that indicates the randomly assigned voting cost in each round of the experiment. Experience takes into consideration the round of the experiment subjects are playing, in order to allow for learning. In models (3) and (4) we specifically control for the order of the sessions, by including the binary variable Order in the regressions. Moreover, in all models, Electoral victories stands for the sum of the individual's elections won period by period, thus controlling for the acquired wealth of participants across time. ${ }^{16}$ In models (3) and (4) we include a measure of individual risk aversion. ${ }^{17}$ In models (2) and (4) we also include the interaction terms FraudI*Majority and FraudII*Majority in order to investigate whether, respectively in Fraud I and Fraud II conditions, the difference in voting behaviour between the majority and the minority group changes with respect

\footnotetext{
${ }^{16}$ More specifically, in models (3) and (4), it is important to include this variable in order to correctly identify the effect of the order of the sessions, since participants' likelihood of winning, when being in the minority and majority group, is also potentially affected by the Order of the sessions. We thank an anonymous referee for providing us with this intuition.

${ }^{17}$ In particular, each subject has to make ten choices between two lotteries, one is more remunerative but more risky, while the other is safer but provides the subject with a lower amount of earnings. See Holt and Laury (2002) for more details on the test. We measure risk aversion as the number of safe choices made by the individual, ignoring possible switching from one type of lottery to another. The analysis reported in this paper changes very little if, as alternative, we drop the 52 subjects who switched more than once from B back to A or vice-versa, the analysis results in minor changes. More specifically, in both models 3 and 4 , the coefficient for mean of voting cost is not significant and mean of electoral victories is significant at $5 \%$ level.
} 
to the Baseline treatment.

First, our variables of interest FraudI (limited fraudulent intervention with 2 ballots) and FraudII (extended fraudulent intervention with 5 ballots) considerably increase the probability of voting. Second, we observe that the coefficient of the Majority variable is significant in both models (1) and (3): in the the Neutral treatment the minority group is more likely to vote than the majority one. FraudI*Majority and FraudII*Majority are never significant, suggesting that the difference in voting behaviour between the minority and the majority group does not depend on the level of electoral integrity.

Finally, in models (3) and (4) we observe that neither the order of the sessions nor the acquired wealth of participants across time significantly affect the probability of voting.

\section{$5.2 \quad$ Framing treatment}

In the previous section we presented evidence of voting behaviour when fake votes are added to the ballot box. Lower turnout is not necessarily observed when comparing elections with and without electoral fraud. In the Neutral treatment we explicitly focus on participants' reactions in a context-free environment. Since the use of abstract terms may eliminate important behavioural considerations that are inherent in elections characterized by an unfair voting procedure, in this section we present a treatment variation designed to investigate the influence of social and psychological factors in affecting voting behaviour. To this end, the entire experiment is framed as an election in the Framing Treatment. In Levine and Palfrey (2007), the authors tested for the effect of framing in their voting experiment but with a limited number of observations (two additional sessions with 9 subjects in each). Our aim is not only to provide additional and more robust evidence on the possible effect of framing the experiment as an election on voter turnout (as in our Baseline condition) but, more importantly, to investigate the effect of framing the experiment as an election with ballot box stuffing (as in our Fraud I and 
Fraud II conditions), which is the main objective of our paper. ${ }^{18}$

162 subjects participated in the Framing treatment, featuring 6 sessions, each with 27 participants. As in the Neutral treatment, 4 Order sessions were characterized by a decreasing quality of elections (i.e. Baseline, Fraud I, Fraud II) while 2 additional sessions were implemented with a Reverse Order (i.e. Fraud II, Fraud I, Baseline), as a robustness check. The experimental procedures, length and average earnings were the same as in the Neutral treatment. In what follows, we describe the main findings on voter turnout with respect to the Baseline, Fraud I and Fraud II conditions.

First, in Table 4, we report the turnout rates under the Baseline condition. As it were the case in the Neutral treatment, we observe over-voting with respect to our theoretical predictions (WSR, Order sessions: $p=0.068$ and $p=0.066$ for the majority and minority group, respectively; Order and Reverse order sessions: $p=0.028$ and $p=0.334$ for the majority and minority groups, respectively; the difference fails to reach significance in the Reverse Order sessions).

\begin{tabular}{|c|c|c|c|}
\hline & Experimental Results & $\begin{array}{c}\text { Framing } \\
\text { Treatment }\end{array}$ & $\begin{array}{l}\text { Theoretical } \\
\text { Equilibrium }\end{array}$ \\
\hline Majority & $\begin{array}{c}\text { Order } \\
\text { Reverse Order } \\
\text { Both }\end{array}$ & $\begin{array}{c}0.342 \\
(0.010) \\
0.308 \\
(0.008) \\
0.331 \\
(0.010)\end{array}$ & 0.228 \\
\hline Minority & $\begin{array}{c}\text { Order } \\
\text { Reverse Order } \\
\text { Both }\end{array}$ & $\begin{array}{c}0.317 \\
(0.025) \\
0.238 \\
(0.072) \\
0.291 \\
(0.030)\end{array}$ & 0.270 \\
\hline
\end{tabular}

Table 4: Turnout rates under the Baseline condition in the Framing treatment (standard error in parentheses).

\footnotetext{
${ }^{18}$ In the instructions we explicitly refer to parties, voting, abstention and ballot box stuffing. See the Appendix for the English version of the experimental instructions.
} 
More interestingly, when comparing turnout between the majority and minority group in the Baseline condition, there is no evidence of greater support for the underdog candidate in the Framing treatment (Order sessions: $p=0.136$, one-sided). Furthermore, the majority party is significantly more likely to vote than the minority one both when considering all sessions together and when limiting our analysis to the Reverse Order ones (Reverse Order: $p=0.09$, one-sided; Order \& Reverse Order: $p=0.058$, one-sided). Result 4 summarizes our main findings:

Result 4. The Framing treatment provides no support for Hypothesis 1: the minority group is not voting at a higher rate than the majority group.

Framing the experiment as an election has some behavioural implications. Voters in majority and minority groups respond differently to such framing. A plausible explanation is the relationship between the electoral frame and the phenomenon of the Incumbency advantage (Freier, 2015, Redmond and Regan, 2015). Previous studies have provided evidence that people have a tendency to vote for the winner or want to be associated with the winner of the elections (Morton and Ou, 2015, Morton et al., 2015). In the Framing treatment, being being part of the minority party may make subjects less likely to vote, since the probability of being associated with the winner is lower.

Figure 3 graphs the voter turnout rate observed in the Baseline, Fraud I and Fraud II conditions in the Framing treatment. 
Figure 3: Voter turnout across periods in the Baseline, Fraud I and Fraud II parts in the Framing treatment.
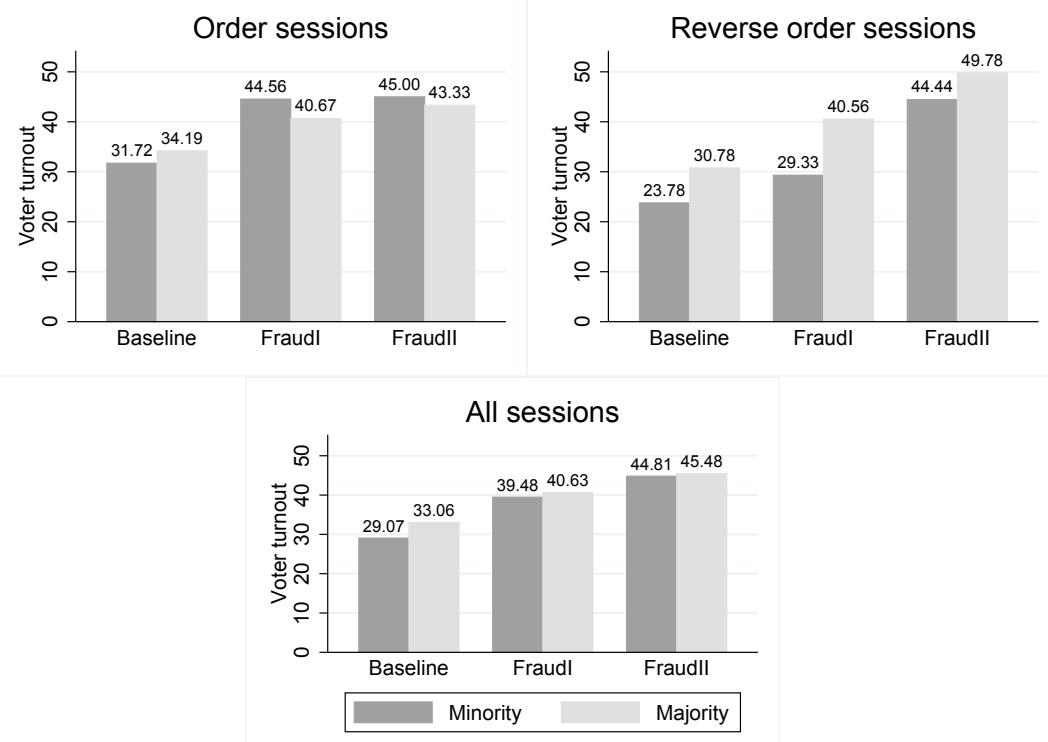

Average voter turnout by group and level of electoral fraud in the Framing treatment.

First, we observe that the turnout significantly increases in Fraud I with respect to the Baseline condition, independently of the party (Order sessions, $p=0.068$ ). The same result hold for both the Order and Reverse Order session together $(p=0.028)$, while the difference in turnout fails to reach significance in the Reverse Order sessions. Second, in Fraud II, voting behaviour follows the opposite pattern than theoretically hypothesised when considering the Framing treatment. Both if restricting the analysis to the Order sessions and if also including the Reverse Order sessions, voter turnout increases in Fraud II condition compared to Fraud I condition, respectively from 41.96 to 43.89 and from 40.25 to 45.26 : voting behaviour observed in our data does not support our predictions when the experiment is framed as an election since there is no significant difference in total turnout between Fraud I and Fraud II. More interestingly, in the Framing treatment, the majority group participated in voting at a significantly higher rate than in the Fraud I condition (WSR test. Order sessions: $p=0.068$; Order \& Re- 
verse Order sessions: $p=0.028) \cdot{ }^{19}$

Result 5. In the Framing treatment hypothesis H2 is rejected: voters do not decrease their participation in the elections as the level of electoral fraud increases. Moreover, voter turnout in the majority group is significantly higher in Fraud II than in Fraud I.

However, the difference fails to reach significance when restricting the analysis to the Reverse Order sessions, most probably due to the limited sample size. In the following individual level analysis we therefore investigate whether voter participation is actually differently affected by the experience of an increase or a decrease in the quality of the voting institution.

Table 5 reports the results of a set of regression models analysing voting behaviour in the Framing treatment. In all models standard errors are clustered at the individual level and the same independent variables already described for Table 3 are included in the analysis. ${ }^{20}$

We first observe that both FraudI and FraudII have a significant effect in increasing the probability of voting, in all models.

On the other hand with respect to the Neutral treatment, in models (1) and (3) the coefficient of the Majority variable is positive and significant, providing evidence that framing the experiment as an election increases the willingness to vote of those in the majority party, with respect to the member of the minority party. Moreover, in model (2) and (4), that also include the interaction terms FraudI*Majority and FraudII*Majority

\footnotetext{
${ }^{19}$ Differences in voter turnout between the Neutral and Framing treatment are mostly observed only with a higher level of electoral fraud, but not for lower levels. Our data thus provide indirect evidence that having loaded instructions rather than neutral ones does not necessarily affect voters' behaviour by influencing their beliefs about others' turnout. Nevertheless, we acknowledge that a proper beliefs elicitation setting is needed in the experimental design in order to clearly distinguish between these two forces.

${ }^{20}$ In table B1 (models (2) and (4)) in the Appendix we replicate the analysis made in models (1) and (2) of Table 5 but we limit our analysis to the Order sessions. Moreover, in Table B2 in the Appendix we also report the coefficients of a Fixed Effect non-linear (logit) model for panel data.
} 
in the regression, the coefficient of Majority is positive and significant, meaning that, in the Baseline condition, the Majority party is significantly less likely to vote than the Minority one when the experiment is framed as an election, differently to what was theoretically hypothesised.

\begin{tabular}{|c|c|c|c|c|}
\hline & $(1)$ & $(2)$ & $(3)$ & (4) \\
\hline FraudI & $\begin{array}{c}0.09508^{* * *} \\
(0.01159)\end{array}$ & $\begin{array}{c}0.11823^{* * *} \\
(0.01887)\end{array}$ & $\begin{array}{c}0.09572^{* * *} \\
(0.01140)\end{array}$ & $\begin{array}{c}0.12171^{* * *} \\
(0.01890)\end{array}$ \\
\hline FraudII & $\begin{array}{c}0.14454^{* * *} \\
(0.01516)\end{array}$ & $\begin{array}{c}0.16702^{* * * *} \\
(0.02104)\end{array}$ & $\begin{array}{c}0.14168^{* * *} \\
(0.01453)\end{array}$ & $\begin{array}{c}0.15844^{* * *} \\
(0.02080)\end{array}$ \\
\hline Majority & $\begin{array}{l}0.02572^{*} \\
(0.01499)\end{array}$ & $\begin{array}{c}0.04296^{* *} \\
(0.02169)\end{array}$ & $\begin{array}{c}0.02627^{*} \\
(0.01532)\end{array}$ & $\begin{array}{l}0.04286^{*} \\
(0.02289)\end{array}$ \\
\hline Voting cost & $\begin{array}{c}-0.01665^{* * *} \\
(0.00047)\end{array}$ & $\begin{array}{c}-0.01665^{* * *} \\
(0.00047)\end{array}$ & $\begin{array}{c}-0.01486^{* * *} \\
(0.00032)\end{array}$ & $\begin{array}{c}-0.01486^{* * *} \\
(0.00032)\end{array}$ \\
\hline Experience & $\begin{array}{l}-0.00111 \\
(0.00144)\end{array}$ & $\begin{array}{l}-0.00103 \\
(0.00144)\end{array}$ & $\begin{array}{l}-0.00157 \\
(0.00140)\end{array}$ & $\begin{array}{l}-0.00151 \\
(0.00140)\end{array}$ \\
\hline Electoral victories & $\begin{array}{c}0.00025 \\
(0.00237)\end{array}$ & $\begin{array}{c}0.00012 \\
(0.00238)\end{array}$ & $\begin{array}{c}0.00086 \\
(0.00231)\end{array}$ & $\begin{array}{c}0.00075 \\
(0.00232)\end{array}$ \\
\hline FraudI*Majority & & $\begin{array}{l}-0.03477 \\
(0.02313)\end{array}$ & & $\begin{array}{l}-0.03886 \\
(0.02406)\end{array}$ \\
\hline FraudII*Majority & & $\begin{array}{l}-0.03418 \\
(0.03018)\end{array}$ & & $\begin{array}{l}-0.02518 \\
(0.03024)\end{array}$ \\
\hline Risk Aversion & & & $\begin{array}{l}-0.00204 \\
(0.00719)\end{array}$ & $\begin{array}{l}-0.00204 \\
(0.00719)\end{array}$ \\
\hline Mean of type & & & $\begin{array}{l}-0.02099 \\
(0.27004)\end{array}$ & $\begin{array}{c}-0.01443 \\
(0.2699)\end{array}$ \\
\hline Mean of voting cost & & & $\begin{array}{l}0.01039^{*} \\
(0.00580)\end{array}$ & $\begin{array}{l}0.01040^{*} \\
(0.00580)\end{array}$ \\
\hline Mean of electoral victories & & & $\begin{array}{c}0.00811 \\
(0.00572)\end{array}$ & $\begin{array}{c}0.00802 \\
(0.00569)\end{array}$ \\
\hline Order & & & $\begin{array}{c}0.01843 \\
(0.02429)\end{array}$ & $\begin{array}{c}0.01864 \\
(0.02428)\end{array}$ \\
\hline Observations & 16200 & 16200 & 16200 & 16200 \\
\hline (Pseudo) R2 & 0.3239 & 0.3242 & 0.2824 & 0.2827 \\
\hline Chi-squared or $\mathrm{F}$ & 262.85 & 199.09 & 573.83 & 574.56 \\
\hline Prob $>$ chi $2 / F$ & 0.000 & 0.000 & 0.000 & 0.000 \\
\hline
\end{tabular}

Table 5: Regression table, Neutral Treatment. Fixed Effects Linear regression model for panel data: (1) and (2). Correlated Random Effects Probit model: (3) and (4). In all models errors are clustered at the individual level.

Finally, as was the case for the Neutral treatment, the order of the sessions has no significant effect on individuals' willingness to vote, even when controlling for the number 
of electoral victories. ${ }^{21}$

\subsection{Electoral fraud and win probability}

Does the incumbent win more often than the other candidate? Is electoral fraud a good strategy for winning elections? In order to answer these questions, in this section we look at the probability of the minority party winning the elections depending on the extent of the electoral fraud and on framing. In the analysis we first focus on both the Order and Reverse Order sessions, and then also provide statistical evidence when limiting the analysis to the Order or to the Reverse Order ones, respectively.

In Figure 4 we report the probability of winning the election for the minority party across treatments and with respect to the model's predictions.

In the Neutral treatment the results of the experiment are closer to our predictions than when considering the Framing treatment. In the Baseline condition the underdog candidate wins in $13 \%$ of the total number of elections when considering all sessions of the Neutral treatment but only in $7.5 \%$ of elections in the Framing one (MW test. Order \& Reverse Order sessions: $p=0.044) .{ }^{22}$ This evidence is consistent with our previous result showing that the majority party over-votes when the experiment is framed as an election with respect to a situation where labels are abstract. When adding two fake ballots to the minority group, as expected, we observe a significant increase in the winning frequency in both the Framing treatment, to $25.67 \%$ (Wilcoxon test. Order \& Reverse Order sessions: $p=0.028$ ), and in the Neutral one, to $27.33 \%$ (Wilcoxon test. Order \& Reverse Order sessions: $p=0.028) .{ }^{23}$

\footnotetext{
${ }^{21}$ As in Table 3, when measuring risk aversion, we are ignoring possible switching from one type of lottery to another. If instead we drop the 52 subjects who switched more than once from B back to A or vice-versa, the analysis results in minor changes. More specifically, in both models 3 and 4, the coefficient for mean of voting cost is not significant and majority is significant at $5 \%$ level.

${ }^{22} \mathrm{~A}$ similar pattern is observed when restricting the analysis to the Order (and Reverse Order) sessions, where the the underdog candidate wins in $12 \%(15 \%)$ and $7 \%(8.5 \%)$ of the elections in the Neutral and Framing treatment, respectively. MW test. Order sessions: $p=0.145$; Reverse Order sessions: $p=0.221$.

${ }^{23}$ The difference between the Baseline and Fraud I is significant $(p=0.068)$ also when considering only the Order sessions (in the Framing treatment and Neutral treatment, the probability of winning the elections increases to $33 \%$ and $32.5 \%$, respectively), but not when limiting the analysis to the Reverse
} 
Figure 4: Probability of winning the elections - Minority party.

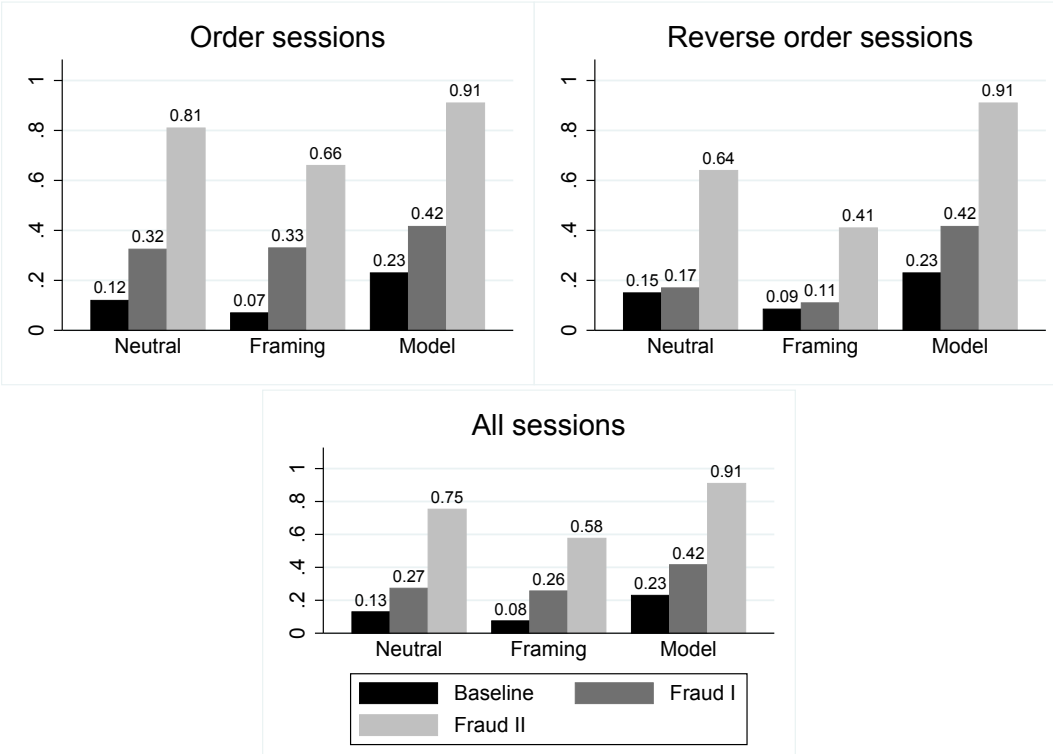

In Fraud I the frequency of the minority party winning the elections in the Framing and in the Neutral treatment is not significantly different. However, when introducing a higher level of electoral fraud, in Fraud II, the minority party is less likely to win the elections in the Framing treatment than in the Neutral treatment: when considering both the Order and Reverse Order sessions together the frequency of victories increases to $57.67 \%$ and to $75.33 \%$ in the Framing and Neutral treatment, respectively (MW test. Order \& Reverse Order sessions: $p=0.092) .{ }^{24,} 25$

Order ones, even if the observed pattern is similar (the probability of winning increases to $11 \%$ in the Framing treatment and to $17 \%$ in the Neutral treatment). )

${ }^{24} \mathrm{~A}$ similar outcome is observed when restricting our analysis to the Order or to the Reverse Order sessions, even if the difference fails to reach significance (Order sessions: $p=0.108$; Reverse Order sessions: $p=0.439)$.

${ }^{25}$ In the current analysis we consider the frequency of winning the elections by the minority party with respect to the total number of elections, also including the tied elections, by comparing data grouped at the session level. When excluding tied elections from our analysis we observe almost the same results, except for the fact that the difference in the probability of winning the elections in the Fraud II condition 
In Table 6, a set of regression models provides additional evidence on the role of behavioural reaction to electoral fraud. Our dependent variable is Minority wins, which is equal to one when the Minority group wins the election and zero otherwise.

First, in model (1) and (2), we present the results of a Fixed Effects linear probability model clustering the errors at the individual level, in order to control for non-observable characteristics of individuals and to correct for autocorrelation bias. In particular, in model (1) we restrict our analysis to the Neutral treatment while in model (2) we focus on the Framing treatment. In model (3) and (4) we report the results of a set of pooled probit models on the same variables of interest, where we also control for the order of the Baseline, Fraud I and Fraud II conditions.

In models (1) and (2) in both the Neutral and Framing treatments, the minority party increases his winning probability with low and high levels of electoral fraud. In model (3) previous results are confirmed and we also observe that the probability that the minority wins the election is significantly higher in the Framing treatment than in the Neutral treatment, as shown by the significance of the coefficient of the Neutral Treatment variable. The effect of the electoral fraud depends on the treatment, as shown in Model (4). The coefficient of the interaction term Neutral*FraudI is negative and significant since the probability of winning with respect to the Baseline condition is more likely to increase in the Framing treatment than in the Neutral one (respectively, from 7.5 to 25.67 and from 13 to 27.33). The coefficient of Fraud II is positive and significant showing that, with respect to the Baseline treatment, adding five fake ballots to the minority party is less effective in increasing the probability of winning the elections for the minority group in the Framing treatment than in the Neutral one (respectively, from 25.67 to 57.67 and from 27.33 to 75.33 ). As shown in the previous paragraph the majority group votes more often when the experiment is framed as an election with five fake ballots than when it is framed in neutral terms, counteracting the effectiveness of between the Framing and Neutral treatment is significant also when considering only the Order sessions (MW test, two-sided, $p=0.081$ ). 
fraud in winning the election.

\begin{tabular}{lcccc}
\hline \hline & $(1)$ & $(2)$ & $(3)$ & $(4)$ \\
\hline FraudI & $0.155000^{* * *}$ & $0.165833^{* * *}$ & $0.173090^{* * *}$ & $0.212648^{* * *}$ \\
& $(0.014704)$ & $(0.017226)$ & $(0.011327)$ & $(0.014042)$ \\
FraudII & $0.541667^{* * *}$ & $0.406667^{* * *}$ & $0.408519^{* * *}$ & $0.387114^{* * *}$ \\
& $(0.013966)$ & $(0.021218)$ & $(0.008559)$ & $(0.015984)$ \\
Experience-FraudI & -0.000897 & $0.001218^{*}$ & 0.000779 & 0.000754 \\
& $(0.000563)$ & $(0.000651)$ & $(0.000473)$ & $(0.000465)$ \\
Experience-FraudII & $0.006282^{* * *}$ & $0.007308^{* * *}$ & $0.004731^{* * *}$ & $0.004813^{* * *}$ \\
& $(0.000600)$ & $(0.001019)$ & $(0.000490)$ & $(0.000507)$ \\
Neutral Tr. & & & $0.087864^{* * *}$ & $0.098241^{* * *}$ \\
& & & $(0.005241)$ & $(0.009569)$ \\
Order & & & $0.084268^{* * *}$ & $0.084048^{* * *}$ \\
& & & $(0.005122)$ & $(0.005089)$ \\
Neutral*FraudI & & & & $-0.076257^{* * *}$ \\
& & & & $(0.014112)$ \\
Neutral*FraudII & & & & $0.044608^{* *}$ \\
& & & & \\
Observations & 16200 & 16200 & 32400 & 32400 \\
Pseudo) R2 & 0.3449 & 0.2601 & 0.2097 & 0.2123 \\
Wald chi2 or F & 11677 & 3287 & 3921.72 & 4591.75 \\
Prob>chi2/F & 0.000 & 0.000 & 0.000 & 0.000 \\
\hline \hline Standard & & & & \\
\hline
\end{tabular}

Standard errors in parentheses

${ }^{*} p<0.10,{ }^{* *} p<0.05,{ }^{* * *} p<0.01$

Table 6: Regression table. Win probabilty, minority group. Linear model for panel data with Fixed Effects: Neutral Treatment (1) and Framing Treatment (2). Probit model: (3) and (4). In all models errors are clustered at the level of individual.

\section{Conclusion}

This paper provides evidence that electoral fraud might increase rather than decrease voter turnout. While a high turnout is usually considered as a signal of a fair election we show, by means of a laboratory experiment, that this is not necessarily the case. Our strategic costly voting model predicts an increase in turnout when the fraudulent intervention is moderate and a sharp drop in participation whenever fraud is pervasive. In the laboratory we test the model's predictions in a very simple setting, investigating voters' behaviour in an environment characterized by a decreasing (increasing) electoral integrity, where the level of electoral fraud is known and exogenously imposed. 
In the Neutral treatment, when the entire setting is defined in abstract terms, the experimental results confirm the first part of our theoretical predictions. However, when a more pervasive fraudulent intervention affects the electoral procedure, our theoretical results are not totally matched: a decrease in participation rates is observed when going from a low to a high level of ballot-box stuffing but still turnout is higher than when full electoral integrity is assured.

In the Framing treatment, when the experiment is explicitly framed as an election, not only is the first part of our theoretical predictions not matched but we also observe that a higher level of electoral fraud increases turnout among the majority group (compared with a low level of fraud). We believe that such behaviour is an attempt by the majority group, that is negatively affected by the illicit intervention, to react to an unfair procedure, even if such action is costly.

Our results are not always matched when limiting the analysis to an electoral system characterized by decreasing integrity (i.e. from a high to a low level of ballot-box stuffing), suggesting that people may react differently when experiencing an increasing vs. decreasing quality of institutions.

Our theoretical predictions are not are not fully reflected in our subjects' behaviour. These differences call for explanations that are beyond pure mistakes in strategic responses. In particular, our model does not allow for the individuals' intrinsic sense of (procedural) fairness, which has been shown to be an important determinant of the individuals' decision making process (Bolton et al., 2005), to affect voter turnout. While in the Neutral treatment, even in the absence of any framing, the inclusion of electoral fraud could already be perceived as a salient phenomenon, in the Framing treatment such an effect is possibly magnified.

Our findings imply that high turnout rates do not necessarily signal that elections are conducted openly and fairly, differently to what has often been observed in empirical studies. However, the complexity of the real world and the unobservability of many 
important variables call for the implementation of the experimental method to allow a better understanding of whether a high turnout rate is actually a good indicator of electoral integrity. Being the first to provide evidence on the role of electoral fraud in affecting voter turnout in a controlled environment, where ceteris paribus comparisons are possible, we decided to keep our setting as simple as possible, abstracting away from many elements of real life in order to cleanly answer our research question. Our experiment can be easily modified to take into account the current limitations of our study. For instance, often in the real world people are confronted with situations where the amount of illicit behaviour in elections is uncertain, rather than having clear knowledge about the level of the illegitimate intervention. Furthermore, we do not consider the relevance of candidates' intentions to illicitly influence the electoral outcome as a possible dimension affecting voters' behaviour. It would be thus interesting to test for the endogeneity of electoral fraud. Finally, it would be fascinating if the perception of electoral fraud were found to be sufficient in positively affecting voter turnout: we might observe that candidates operate to influence this perception, rather than to actually rig the electoral system. This type of research can potentially inform current research on the role of fake news, aimed at influencing perception of electoral fraud. 


\section{Compliance with Ethical Standards}

In this paper we implemented a set of laboratory experiments with human subjects run at the University of Milano Bicocca. The study did not involve any risk for participants. Informed consent was obtained following the procedures of the laboratory at the University of Milano Bicocca and possible consequences of the study were explained to all participants, who were free to quit the study at any time with no penalties.

Funding: This study was funded by PRIN (2012-2015) "New approaches to political economics : positive political theories, empirical evidence and experiments in laboratory".

Conflict of Interest: The authors declare that they have no conflict of interest.

\section{References}

Abbink, K. and Hennig-Schmidt, H. . (2006). Neutral versus loaded instructions in a bribery experiment. Experimental Economics, 9:103-121.

Aimone, J. A., Butera, L., and Stratmann, T. (2017). Altruistic punishment in elections. European Journal of Political Economy.

Bader, M. (2012). Trends and patterns in electoral malpractice in post-soviet eurasia. Journal of Eurasian Studies, 3:49-57.

Birch, S. (2010). Perceptions of electoral fairness and voter turnout. Comparative Political Studies, 43(12):1601-1622.

Bolton, G. E., Brandts, J., and Ockenfels, A. (2005). Fair procedures: Evidence from games involving lotteries. The Economic Journal, 115(506):1054-1076.

Bratton, M. (2008). Vote buying and violence in nigerian election campaigns. Electoral Studies, 27:621-632. 
Butler, M. and Marchal, M. A. (2007). Framing effects in political decision making: Evidence from a natural voting experiment. CESifo Working Paper Series 1940.

Carreras, M. and İrepoğlu Yasemin (2013). Trust in elections, vote buying, and turnout in latin america. Electoral Studies, 32(4):609-619.

Collier, P. and Hoeffler, A. (2009). Democracys achilles heel or, how to win an election without really trying. Working paper series Centre for the Study of African Economies, Department of Economics, Oxford.

Collier, P. and Vicente, P. C. (2012). Violence, bribery, and fraud: the political economy of elections in sub-saharan africa. Public choice, 153(1):117-147.

Deutsch, M. (1975). Equity, equality, and need: What determines which value will be used as the basis of distributive justice? Journal of Social Issues, 31(3).

Douglas, J. A. (2013). Procedural fairness in election contests. Indiana Law Journal, 88.

Druckman, J. N. (2001). On the limits of framing effects: Who can frame? The Journal of Politics, 63(4):1041-1066.

Druckman, J. N. (2004). Political preference formation: Competition, deliberation and the (ir)relevance of framing effects. American Political Science Review, 98(4):671-686.

Duffy, J. and Tavits, M. (2008). Beliefs and voting decisions: A test of the pivotal voter model. American Journal of Political Science, 52:603-618.

Ellman, M. and Wantchekon, L. (2000). Electoral competition under the threat of political unrest. The Quarterly Journal of Economics, 115(2):499-531.

Enikolopov, R., Korovkin, V., Petrova, M., Sonin, K., and Zakharov, A. (2013). Field experiment estimate of electoral fraud in russian parliamentary elections. PNAS, 110(2):448-452. 
Fischbacher, U. (2007). z-tree: Zurich toolbox for ready-made economic experiments. Experimental Economics, 10:171-178.

Fischbacher, U. and Föllmi-Heusi, F. (2013). Lies in disguise an experimental study on cheating. Journal of the European Economic Association, 11(3):525-547.

Freier, R. (2015). The mayor's advantage: Causal evidence on incumbency effects in german mayoral elections. European Journal of Political Economy, 40:16-30.

Fukumoto, K. and Horiuchi, Y. (2011). Making outsiders' votes count: Detecting electoral fraud through a natural experiment. American Political Science Review, 105(3):586-603.

Greiner, B. (2004). An online recruitment system for economic experiments. Forschung und wissenschaftliches Rechnen 2003. GWDG Bericht, 63:79-93.

Grosser, J., Kugler, T., and Schram, A. (2005). Preference uncertainty, voter participation and electoral efficiency: An experimental study. University of Cologne. Working Paper Series in Economics.

Grosser, J. and Schram, A. (2010). Public opinion polls, voter turnout, and welfare: An experimental study. American Journal of Political Science, 54(3):700-717.

Holt, C. A. and Laury, S. K. (2002). Risk aversion and incentive effects. American Economic Review, 92(5):1644-1655.

Houser, D., Morton, R., and Stratmann, T. (2011). Turned on or turned out? campaign advertising, information and voting. European Journal of Political Economy, $27(4): 708-727$.

Houser, D. and Stratmann, T. (2008). Selling favors in the lab: experiments on campaign finance reform. Public Choice, 136(1):215-239. 
Lehoucq, F. E. (2002). Stuffing the ballot box: Fraud, electoral reform and democratization in Costa Rica. Cambridge University Press.

Levine, D. K. and Palfrey, T. R. (2007). The paradox of voter participation? a laboratory study. American Political Science Review, 101(1):143-158.

McCann, J. A. and Dominguez, J. I. (1998). Mexicans React To Electoral Fraud And Political Corruption: An Assessment Of Public Opinion And Voting Behavior. Elsevier.

Minnite, L. and Callahan, D. (2003). Securing the vote: an analysis of election fraud. Demos, 14.

Morton, R. B., Muller, D., Page, L., and Torgler, B. (2015). Exit polls, turnout, and bandwagon voting: Evidence from a natural experiment. European Economic Review, $77: 65-81$.

Morton, R. B. and Ou, K. (2015). What motivates bandwagon voting behavior: Altruism or a desire to win? European Journal of Political Economy, 40:224-241.

Mundlak, Y. (1978). On the pooling of time series and cross section data. Econometrica, 46(1):69-85.

Norris, P. (2014). Why Electoral Integrity Matters. Cambridge University Press.

Paetzel, F., Lorenz, J., and Tepe, M. (2017). Transparency diminishes framing-effects in voting on redistribution: Some experimental evidence. European Journal of Political Economy.

Palfrey, T. R. (2009). Laboratory experiments in political economy. Annual Review of Political Science, 12:379-388.

Palfrey, T. R. and Rosenthal, H. (1985). Voter participation and strategic uncertainty. American Political Science Review, 79(1):62-78. 
Redmond, P. and Regan, J. (2015). Incumbency advantage in a proportional electoral system: A regression discontinuity analysis of irish elections. European Journal of Political Economy, 38:244-256.

Schnellenbach, J. and Schubert, C. (2015). Behavioral political economy: A survey. European Journal of Political Economy, 40:395-417.

Schram, A. and Sonnemans, J. (1996). Why people vote: Experimental evidence. Journal of Economic Psychology, 17(4):417-442.

Schuck, A. R., Vliegenthart, R., and De Vreese, C. H. (2014). Who's afraid of conflict? the mobilizing effect of conflict framing in campaign news. British Journal of Political Science:, pages 1-18.

Schuck, A. R. T., Vliegenthart, R., Boomgaarden, H. G., Elenbaas, M., Azrout, R., van Spanje, J., and de Vreese, C. H. (2013). Explaining campaign news coverage: How medium, time and context explain variation in the media framing of the 2009 european parliamentary elections. Journal of Political Marketing, 12(1):8-28.

Simpser, A. (2013). Why Governments and Parties Manipulate Elections: Theory, Practice, and Implications. Cambridge University Press.

Tarrow, S. (1998). Power in Movement: social movements and contentious politics. Cambridge University Press.

Valentino, N. A., Beckmann, M. N., and Buhr, T. A. (2001). A spiral of cynicism for some: The contingent effects of campaign news frames on participation and confidence in government. Political Communication, 18(4):347-367.

van Winden, F. (2015). Political economy with affect: On the role of emotions and relationships in political economics. European Journal of Political Economy, 40:298 311. Behavioral Political Economy. 
Vergne, C. (2009). Turnout in developing countries: The effect of mass media on national voter participation. Center for Studies and Researches on International Development CERDI.

Vorobyev, D. (2016). Participation in fraudulent elections. Social choice and welfare, $46(4): 863-892$.

Wilking, J. R. (2011). The portability of electoral procedural fairness: Evidence from experimental studies in china and the united states. Political Behavior, 33(1):137-159.

Wilks-Heeg, S. (2008). Purity of elections in the uk: Causes for concern. Technical report, The Joseph Rowntree Reform Trust Ltd.

Wolak, J. (2014). How campaigns promote the legitimacy of elections. Electoral Studies, 34:205-215. 


\title{
Electoral fraud and voter turnout: An experimental study
}

\author{
Vardan Baghdasaryan; Giovanna Iannantuoni† Valeria Maggian
}

\footnotetext{
${ }^{*}$ American University of Armenia and Affiliate Fellow at CERGE-EI, Prague. E-mail: vbaghdasaryan@aua.am.

${ }^{\dagger}$ University of Milano-Bicocca. E-mail: giovanna.iannantuoni@unimib.it.

${ }^{\ddagger}$ Corresponding author. Cà Foscari University, Department of Economics, Cannaregio 873, Fondamenta San Giobbe, 30121 Venice, Italy. E-mail: valeria.maggian@unive.it.
} 


\section{Appendix A}

\section{EXPERIMENTAL INSTRUCTIONS}

The instructions written in red refer to the NEUTRAL treatment, while the instructions written in italics green refer to the FRAMING treatment.

\section{SESSION 1}

\section{SCREEN 1}

Thanks for agreeing to participate in this research experiment.

During the experiment we require your complete, undistracted attention. We ask you to follow the instructions carefully. Turn off your mobile phones. You cannot use mobile phones and you cannot talk with other participants. If you have any questions please raise your hand.

The choices you are going to make during the experiment will be completely anonymous. It will be impossible for those analyzing the data to know participants identity.

For your participation, you will be paid in cash, at the end of the experiment. Different participants may earn different amounts. What you earn depends partly on your decisions, partly on the decisions of others, and partly on chance. So it is important that you listen carefully, and fully understand the instructions before we begin.

There will be a short comprehension quiz after the instructions reading, which you all need to pass before we can begin the paid sessions.

If you encounter any difficulty during the questionnaire, please raise your hand.

\section{SCREEN 2}

Everyone will be paid in private and you are under no obligation to tell others how much you earned. Your earnings during the experiment are denominated in POINTS. Your EURO earnings are determined by multiplying your earnings in POINTS by a conversion rate. In this experiment, the conversion rate is 0.0012 , meaning that 100 POINTS is worth 12 cents.

The experiment consists of 2 different sessions. Each session will consist of 50 rounds. At the end of the last paid session, you will be paid the sum of what you have earned in the two sessions : the points you have earned will be converted into Euro and privately given to you in cash. 


\section{SCREEN 3}

Now we are explaining you the detailed instructions for the first session of the experiment.

The first session consists of 50 rounds.

At the beginning of each round of the first session you will be randomly assigned to the ALPHA or BETA group party.

You will be then informed about which group party you are part of and about the number of members of each group party.

ALPHA group party has 9 members and the BETA group party has 18 members.

Moreover, to each participant it will be also randomly assigned a bonus Y. We will explain what this means in a moment.

After that, you will be asked to choose one option out of two: option "X" to vote or option "Y" to abstain. In order to make a choice you just have to select one of the two options and click on the OK button on your screen.

Your earnings depend on your choice of either option "X" to vote or option "Y" to abstain and on which group party. has the most members choosing option "X" to vote. After every participant has made a choice between the two options, your earnings will be showed on your screen.

\section{SCREEN 4}

How are your earnings determined in every period?

It is very important that you understand this, so please listen carefully.

Suppose you choose option "X" to vote. If your group party has more members choosing option "X" to vote than the other group party, then you will earn 105 points; if both groups parties have the same number of members choosing option " $\mathrm{X}$ " to vote, then you will earn 55 points, and if the other group party has more members choosing option "X" to vote, than your group party, then you will earn 5 points.

Alternatively, suppose you choose option "Y" to abstain. If your group party has more members choosing option "X" to vote than the other group party, then you will earn 105 points plus your Y bonus; if both groups parties have the same number of members choosing option "X" to vote, then you will earn 55 points plus your $\mathrm{Y}$ bonus, and if the other group party has more members choosing option " $\mathrm{X}$ " to vote than your group party, then you will earn 5 points plus your Y bonus. 
The amount of your Y-bonus is assigned randomly by the computer and is shown on your screen. In any given round you have an equal chance of being assigned any Y-bonus between 0 and 55 points. Your Y-bonus in each round does not depend on your Y-bonus or decisions in previous rounds, or on the Y-bonuses and decisions of other participants. Since Y-bonuses are assigned separately for each participant, different participants will typically have different Y-bonuses. While you are told your own Y-bonus, you are never told the Y-bonuses of other participants. You only know that each of the other participants has a Y-bonus that is some number between 0 and 55.

\section{SCREEN 5}

Here is an example: Suppose that one member of the ALPHA group party choose option "X" to vote and two members of the BETA group party choose option "X" to vote.

Then the BETA group party has more members choosing option "X" to vote than ALPHA. Each member of the ALPHA group party who chose option "X" to vote earns 5 points; each member of the ALPHA group party who chose option "Y" to abstain earns 5 points plus his or her own personal Y-bonus ; the members of the BETA group party who chose option "X" to vote earn 105 points, and each member of the BETA group party who chose option "Y" to abstain earns 105 points plus his or her personal Y-bonus.

The bottom of the screen contains a history panel. During the various sessions and rounds, this panel will be updated to reflect the history of your past sessions.

After you and the other participants have all made your choices of option "X" to vote or option "Y" to abstain, the screen will change to highlight the row corresponding to your own choice, and the column of the group party which had the greatest number of members choose option "X" to vote. At the end of each round until the session ends, you will be randomly divided between groups parties, and will have the opportunity to choose between option "X" to vote and option "Y" to abstain. In other words, you will not necessarily be in the same group party during each round.

\section{SCREEN 6}

If you have any questions at this time, please raise your hand.

Now you are going to answer a quiz to be sure everyone has correctly understood the instructions. Please read each question carefully and check the correct answer. 
Once everyone has answered the questions correctly, you may all go on to the second stage of the quiz. After successfully completing the second round of questions, we will commence with the first session.

If you have any difficulties with the quiz or have other questions please your hand.

Participants answer the quiz. 


\section{QUIZ}

1. How many members are in the Alpha group party?
(a) 9
(b) 18
(c) 27

2. How many members are in the Beta group party?
(a) 9
(b) 18
(c) 27

3. Are group party assignments randomly reassigned after every round?
(a) yes
(b) no

4. Is your $\mathrm{Y}$ bonus necessarily the same as other members of your group party?
(a) yes
(b) no

5. Suppose in round 1 you are assigned to b a member of the Beta group party. Moreover, suppose your randomly assigned $\mathrm{Y}$ bonus in this round is equal to 21 points.

- Suppose you choose option "X" to vote. Totally (you are included), three members of the Beta group party and four members of the Alpha group party chose option "X" to vote. How many points do you earn in this round?
(a) 5
(b) 21
(c) 26
(d) 55 
(e) 76

(f) 105

- Suppose you choose option "Y" to abstain.

Totally (you are included), four members of the Beta group party and four members of the Alpha group party chose option "X" to vote. How many points do you earn in this round?
(a) 5
(b) 21
(c) 26
(d) 55
(e) 76
(f) 105 


\section{READY}

Let me summarize those rules before we start. Please listen carefully.

In each round of this session, 9 participants will be randomly assigned to the Alpha group party and 18 participants will be assigned to the Beta group party.

You may choose option "X" to vote or option "Y" to abstain.

If you choose option "X" to vote, your payoff will be 105 POINTS if your group party has more members choosing option "X" to vote than the other group party, 5 POINTS if your group party has fewer members choosing option " $\mathrm{X}$ " to vote, and 55 POINTS if it is a tie. If you choose option "Y" to abstain, you will also receive the Y-bonus shown on your screen. There will be 50 rounds in this session.

After each round, group party assignments will be randomly reshuffled. Therefore, in some rounds you will be in the Alpha group party and in other rounds you will be in the Beta group party.

In either case, everyone is told which group party they are in before making a choice of option "X" to vote or option "Y" to abstain.

Please begin. (Play rounds 1 to 50). 


\section{SESSION 2}

We will now begin session 2 .

\section{$F R A U D$}

\section{SCREEN 7}

Session 1 is now over.

We will now begin session 2 .

The second session will be slightly different from the first session. Let me summarize those rules before we start. Please listen carefully.

Differently than in the previous session, now a vote rigging is affecting the electoral system. in each of the first 25 rounds of this second session, 2 units votes will be automatically added to the sum of option "X" votes by the ALPHA group party in order to compute which group party has the highest number of option "X" votes.

As in the previous session you will be informed whether you are part of the ALPHA or BETA group party and of the amount of your Y bonus.

You may choose option "X" to vote or option "Y" to abstain. After you and the other participants have all made your choices of option "X" to vote or option "Y" to abstain the screen will change to highlight the row corresponding to your own choice, and the column of the group which had the greatest number of members who choose option "X" votes.

\section{READY2}

In each round of this session, 9 participants will be randomly assigned to the Alpha group party and 18 participants will be assigned to the Beta group party.

You may choose option "X" to vote or option "Y" to abstain.

If you choose option "X" to vote, your payoff will be 105 POINTS if your group party has more members choosing option "X" to vote than the other group party, 5 POINTS if your group party has fewer members choosing option " $\mathrm{X}$ " to vote, and 55 POINTS if it is a tie. If you choose option "Y" to abstain, you will also receive the Y-bonus shown on your screen. There will be 50 rounds in this session.

After each round, group party assignments will be randomly reshuffled. Therefore, in 
some rounds you will be in the Alpha group party and in other rounds you will be in the Beta group party.

In either case, everyone is told which group party they are in before making a choice of option "X" to vote or option "Y" to abstain.

Now, because of the vote rigging, in order to compute which group party has the highest number of option "X" selected votes, in every round 2 units votes, will be automatically added to the ALPHA group party. Please begin.

(Play rounds 51 to 75)

\section{SCREEN 8}

In each of the first 25 rounds of this second session, there is still a vote rigging affecting the electoral process: 5 units votes will be now automatically added to the sum of option "X" votes by the ALPHA group party in order to compute which group party has the highest number of option "X" votes.

As in the previous session you will be informed whether you are part of the ALPHA or BETA group party and of the amount of your Y bonus.

You may choose option "X" to vote or option "Y" to abstain. After you and the other participants have all made your choices of option "X" to vote or option "Y" to abstain the screen will change to highlight the row corresponding to your own choice, and the column of the group which had the greatest number of members who choose option "X" votes.

\section{READY3}

Let me summarize those rules before we start. Please listen carefully.

In each round of this session, 9 participants will be randomly assigned to the Alpha group party and 18 participants will be assigned to the Beta group party.

You may choose option "X" to vote or option "Y" to abstain.

If you choose option " $\mathrm{X}$ " to vote, your payoff will be 105 POINTS if your group party has more members choosing option "X" to vote than the other group party, 5 POINTS if your group party has fewer members choosing option "X" to vote, and 55 POINTS if it is a tie. If you choose option "Y" to abstain, you will also receive the Y-bonus shown 
on your screen. There will be 50 rounds in this session.

After each round, group (party) assignments will be randomly reshuffled. Therefore, in some rounds you will be in the Alpha group party and in other rounds you will be in the Beta group party.

In either case, everyone is told which group party they are in before making a choice of option "X" to vote or option "Y" to abstain.

Now, because of the vote rigging, in order to compute which group party has the highest number of option " $\mathrm{X}$ " selected votes, in every round 5 units votes, will be automatically added to the ALPHA group party.

Please Begin. (Play rounds 75 to 100)

Session 2 is now over. 


\section{SESSION $3-$ H \& L}

In the next screen you will be asked to make 10 decisions. Each decision is a paired choice between "Option A" and "Option B."

You will make ten choices and record these in the final column, but only one of them will be used in the end to determine your earnings.

Before you start making your ten choices, please let me explain how these choices will affect your earnings for this part of the experiment.

After you have made all of your choices, the computer will randomly extract a random number between 1 and 10 included for two times. The first randomly extracted number is used to select one of the ten decisions to be used, and the second to determine what your payoff is for the option you chose, A or B, for the particular decision selected.

Even though you will make ten decisions, only one of these will end up affecting your earnings, but you will not know in advance which decision will be used.

Obviously, each decision has an equal chance of being used in the end.

Now, please look at Decision 1 at the top. Option A pays 2 Euro if the second random number extracted is 1 , and it pays 1.60 Euro if the second random extracted number is 2-10. Option B yields 3.85 Euro if the second random number extracted is 1, and it pays 0.10 Euro if it is $2-10$.

The other Decisions are similar, except that as you move down the table, the chances of the higher payoff for each option increase. In fact, for Decision 10 in the bottom row, the second random number to extracted will not be needed since each option pays the highest payoff for sure, so your choice here is between 2 Euro or 3.85 Euro.

To summarize, you will make ten choices: for each decision row you will have to choose between Option A and Option B.

You may choose A for some decision rows and B for other rows, and you may change your decisions and make them in any order.

When you are finished, the computer will extract a first random number between 1 and 10 to decide which of the ten Decisions will be used. Then the computer will extract a second random number between 1 and 10 to determine your money earnings for the Option you chose for that Decision. Earnings (in Euro) for this choice will be added to your previous earnings, and you will be paid all earnings in cash when we finish.

Are there any questions? Now you may begin making your choices. Please do not 
talk with anyone while we are doing this; raise your hand if you have a question.

Please Begin. (Play H \& L test for risk aversion).

Once it is finished, start the demographic questionnaire.

\section{QUESTIONNAIRE}




\section{Appendix B}

In the following tables we integrate the analysis contained in Table 3 and 5 of the main text, where the voting decision is investigated by including observations of both the Order and Reverse Order sessions.

First, in Table B1, we report the coefficients of a set of Fixed Effects Linear regression models for panel data, only including observations of the Order sessions. In all models, errors are clustered at the individual level. More specifically, in models (1) and (3) of Table B1 we replicate the same analysis of the Neutral treatment made in Table 3 in the main text (models 1-2). We observe that our results with respect to the Neutral treatment are unchanged when limiting our analysis to the Order sessions of the Neutral treatment. In models (2) and (4) we analyse the Framing treatment, as in model (1) and (2) of Table 5 in the main text, with the only difference of limiting our analysis to the Order sessions. The most relevant difference is observed in model (2) where the coefficient of Majority has the expected sign but does not reach significance. Moreover, in model (4), the coefficient of the interaction term FraudI*Majority is significant while the coefficient of Majority is not, differently than in Table .5 In table B2, the significant coefficient of FraudI*Majority indicates that the effect of framing the fraudulent intervention as a ballot-box stuffing differently affects the minority and the majority group in the Fraud I game, while this is not the case if we also include in the analysis the Reverse Order sessions.

In models (1) and (2) of Table B2, we report the results of a Fixed Effects non-linear (logit) model for panel data. In specification (1) and (2) we include observations of both the Order and Reverse Order sessions of the Neutral and Framing treatment, respectively. In models (3) and (4) we replicate the previous analysis but only including observations of the Order sessions. We do not observe big differences with respect to the results reported in models (1) of Table 3 and 5, respectively for the Neutral and Framing treatments. In particular, the most relevant difference is noted when limiting our analysis to the Order sessions of the Framing treatment: the majority party is not more likely to vote than the minority one, on average (i.e. without allowing for the presence of electoral fraud to differently affect the majority party's voting behavior). 
Table B.1: Regression table, Fixed Effects Linear regression model for panel data. In all models errors are clustered at the individual level.

\begin{tabular}{lcccc}
\hline \hline & $(1)$ & $(2)$ & $(3)$ & $(4)$ \\
& Neutral Tr. & Framing Tr. & Neutral Tr. & Framing Tr. \\
\hline FraudI & $0.12287^{* * *}$ & $0.16347^{* * *}$ & $0.13539^{* * *}$ & $0.21454^{* * *}$ \\
& $(0.01755)$ & $(0.01882)$ & $(0.02271)$ & $(0.02739)$ \\
FraudII & $0.14380^{* * *}$ & $0.22193^{* * *}$ & $0.15711^{* * *}$ & $0.25581^{* * *}$ \\
& $(0.02980)$ & $(0.03290)$ & $(0.03665)$ & $(0.03858)$ \\
Majority & $-0.04385^{* *}$ & 0.00107 & -0.03406 & 0.03307 \\
Voting cost & $(0.01904)$ & $(0.01706)$ & $(0.02391)$ & $(0.02686)$ \\
Experience & $-0.01729^{* * *}$ & $-0.01686^{* * *}$ & $-0.01729^{* * *}$ & $-0.01687^{* * *}$ \\
& $(0.00062)$ & $(0.00055)$ & $(0.00062)$ & $(0.00055)$ \\
Electoral victories & -0.00119 & $-0.00340^{*}$ & -0.00113 & $-0.00332^{*}$ \\
& $(0.00186)$ & $(0.00202)$ & $(0.00186)$ & $(0.00201)$ \\
FraudI*Majority & -0.00014 & 0.00210 & -0.00024 & 0.00196 \\
& $(0.00307)$ & $(0.00319)$ & $(0.00307)$ & $(0.00318)$ \\
FraudII*Majority & & & -0.01874 & $-0.07664^{* *}$ \\
& & & $(0.02125)$ & $(0.03065)$ \\
\hline Observations & 10800 & 10800 & 10800 & 10800 \\
R2 & 0.3363 & 0.3283 & 0.3364 & 0.3292 \\
Frob¿F & 187.73 & 202.56 & 161.38 & 160.96 \\
\hline \hline
\end{tabular}

Clustered Standard errors in parentheses

${ }^{*} p<0.10,{ }^{* *} p<0.05,{ }^{* * *} p<0.01$ 
Table B.2: Regression table. Logit model for panel data with Fixed effects. Neutral treatment, all sessions (1) and Order sessions (3); Framing treatment, all sessions (2) and Order sessions (4).

\begin{tabular}{lcccc}
\hline \hline & $(1)$ & $(2)$ & $(3)$ & $(4)$ \\
& Neutral Tr. & Framing Tr. & Neutral Tr. & Framing Tr. \\
\hline FraudI & $0.05285^{* * *}$ & $0.06694^{* * *}$ & $0.06799^{* * *}$ & $0.10169^{* * *}$ \\
& $(0.00461)$ & $(0.00530)$ & $(0.00708)$ & $(0.00788)$ \\
FraudII & $0.06437^{* * *}$ & $0.09760^{* * *}$ & $0.08038^{* * *}$ & $0.13548^{* * *}$ \\
& $(0.00484)$ & $(0.00585)$ & $(0.01034)$ & $(0.01138)$ \\
Majority & $-0.01977^{* * *}$ & $0.01748^{* * *}$ & $-0.02445^{* * *}$ & 0.00095 \\
& $(0.00327)$ & $(0.00436)$ & $(0.00368)$ & $(0.00453)$ \\
Voting cost & $-0.00898^{* * *}$ & $-0.01001^{* * *}$ & $-0.00836^{* * *}$ & $-0.00892^{* * *}$ \\
& $(0.00022)$ & $(0.00020)$ & $(0.00033)$ & $(0.00031)$ \\
Experience & -0.00066 & -0.00080 & -0.00069 & $-0.00203^{* * *}$ \\
Electoral victories & $(0.00044)$ & $(0.00057)$ & $(0.00053)$ & $(0.00066)$ \\
& 0.00043 & 0.00023 & -0.00002 & 0.00119 \\
Observations & $(0.00075)$ & $(0.00095)$ & $(0.00086)$ & $(0.00105)$ \\
Sessions & 16200 & 16200 & 10800 & 10800 \\
Pseudo R2 & All & All & Order & Order \\
LR Chi-squared & .36461729 & .34698616 & .36145939 & .34504641 \\
Prob>chi2 & 7078.48 & 6689.58 & 4648.74 & 4476.73 \\
\hline \hline
\end{tabular}

Standard errors in parentheses

${ }^{*} p<0.10,{ }^{* *} p<0.05,{ }^{* * *} p<0.01$ 